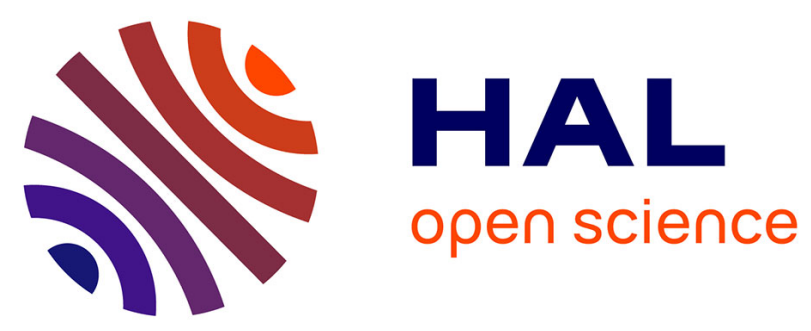

\title{
Beta-arrestins operate an on/off control switch for Focal Adhesion Kinase activity
}

Revu Ann Alexander, Isaure Lot, Kusumika Saha, Guillaume Abadie, Mireille Lambert, Eleonore Decosta, Hiroyuki Kobayashi, Alexandre Beautrait, Aurélie Borrull, Atef Asnacios, et al.

\section{To cite this version:}

Revu Ann Alexander, Isaure Lot, Kusumika Saha, Guillaume Abadie, Mireille Lambert, et al.. Betaarrestins operate an on/off control switch for Focal Adhesion Kinase activity. Cellular and Molecular Life Sciences, 2020, Epub ahead of print. 10.1007/s00018-020-03471-5 . inserm-02498844

\section{HAL Id: inserm-02498844 https://www.hal.inserm.fr/inserm-02498844}

Submitted on 4 Mar 2020

HAL is a multi-disciplinary open access archive for the deposit and dissemination of scientific research documents, whether they are published or not. The documents may come from teaching and research institutions in France or abroad, or from public or private research centers.
L'archive ouverte pluridisciplinaire HAL, est destinée au dépôt et à la diffusion de documents scientifiques de niveau recherche, publiés ou non, émanant des établissements d'enseignement et de recherche français ou étrangers, des laboratoires publics ou privés. 


\section{Beta-arrestins operate an on/off control switch \\ for Focal Adhesion Kinase activity}

Revu Ann Alexander ${ }^{1}$, Isaure Lot ${ }^{1}$, Kusumika Saha ${ }^{1}$, Guillaume Abadie ${ }^{1}$, Mireille Lambert ${ }^{1}$, Eleonore Decosta ${ }^{1}$, Hiroyuki Kobayashi ${ }^{2}$, Alexandre Beautrait ${ }^{2}$, Aurélie Borrull ${ }^{1}$, Atef Asnacios ${ }^{3}$, Michel Bouvier ${ }^{2}$, Mark G. H. Scott $^{1}$, Stefano Marullo ${ }^{1}$ and Hervé Enslen ${ }^{1 *}$

${ }^{1}$ : Institut Cochin, Inserm U 1016, CNRS UMR8104, Université de Paris, Paris, France.

2 : Department of Biochemistry and the Institute for Research in Immunology and Cancer, Université de Montréal, Montréal, Québec H3C 3J7, Canada.

${ }^{3}$ : Laboratoire Matière et Systèmes Complexes, CNRS UMR 7057, Université de Paris, Paris, France.

(*) Corresponding author: herve.enslen@inserm.fr

Address: Institut Cochin, Inserm U 1016, CNRS UMR8104, Université de Paris

27 rue du Faubourg Saint-Jacques, 75014 Paris, France.

Tel: +33140516554

Fax: +33140516535

\section{Acknowledgements}

The authors are grateful to Dr RJ Lefkowitz (Duke University, USA) for providing the $\beta$-arr mouse embryonic fibroblasts, to Dr R. Leduc for the HEK-AT ${ }_{1 \mathrm{~A}} \mathrm{R}$ cell line and to Dr E. Escher (Universite de Sherbrook, Canada) for the gift of the biased ligand, to Dr A. Benmerah (Imagine-INSERM-U1163, France), Dr J-A Girault (Institut Fer-à-Moulin, INSERM-839, France), Dr S Laporte (McGill University, Canada) and Dr A.N.Shrivastava (IBENS CNRS-UMR8197, Inserm-U1024, France), for providing reagents, to M. Sierks for help with the MEFs work and to J. Paradis (IRIC, Université de Montréal, Canada) for helpful discussion. Funding: This work was supported by La Ligue Contre le Cancer, Comité de l'Oise to H. Enslen; the Fondation pour la Recherche Médicale ("Team FRM") to S. Marullo. The S. Marullo team is supported by the Inserm, the CNRS, the Université de Paris and is a member of the "Who am I?" LABoratory of EXcellence (grant ANR-11-LABX0071) funded by the "Investments for the Future" program operated by The French National Research Agency (grant ANR-11-IDEX-0005-01). RA Alexander was supported by FRM and the Who am I? LABoratory of EXcellence. M. Bouvier is supported by a Foundation grant from CIHR and holds the Canada Research Chair in Signal Transduction and Molecular Pharmacology.

\section{ABBREVIATIONS}

AP-2, adaptor protein $2 ; \mathrm{AT}_{1 \mathrm{~A}} \mathrm{R}$, angiotensin II type 1 receptor; $\beta$-arr, $\beta$-arrestin; BRET, Bioluminescence Resonance Energy Transfer; FA, focal adhesion; FERM, 4.1, ezrin, radixin, moesin; GFP, green fluorescent protein; MEF, mouse embryonic fibroblast; SiRNA, small interfering RNA; WT, wild type; YFP, yellow fluorescent protein 


\section{ABSTRACT}

FAK (Focal Adhesion Kinase) regulates key biological processes downstream of G Protein Coupled Receptors (GPCRs) in normal and cancer cells, but the modes of kinase activation by these receptors remain unclear. We report that after GPCR stimulation FAK activation is controlled by a sequence of events depending on the scaffolding proteins $\beta$-arrestins and $G$ proteins. Depletion of $\beta$-arrestins result in a marked increase in FAK autophosphorylation and focal adhesion number. We demonstrate that $\beta$-arrestins interact directly with FAK and inhibit its autophosphorylation in resting cells. Both FAK- $\beta$-arrestin interaction and FAK inhibition require the FERM domain of FAK. Following the stimulation of the angiotensin receptor $\mathrm{AT}_{1 \mathrm{~A}} \mathrm{R}$ and subsequent translocation of the FAK- $\beta$ arrestin complex to the plasma membrane, $\beta$-arrestin interaction with the adaptor AP-2 releases inactive FAK from the inhibitory complex, allowing its activation by receptor-stimulated G proteins and activation of downstream FAK effectors. Release and activation of FAK in response to angiotensin are prevented by an AP-2-binding deficient $\beta$ arrestin and by a specific inhibitor of $\beta$-arrestin/AP-2 interaction; this inhibitor also prevents FAK activation in response to vasopressin. This previously unrecognized mechanism of FAK regulation involving a dual role of $\beta$ arrestins, which inhibit FAK in resting cells while driving its activation at the plasma membrane by GPCR-stimulated G proteins, opens new potential therapeutic perspectives in cancers with up-regulated FAK.

Keywords: G-protein coupled receptors; beta-arrestin ; $\beta$-arrestin; AP-2 ; FAK, G proteins 


\section{INTRODUCTION}

Focal Adhesion Kinase (FAK), a highly conserved non-receptor tyrosine kinase [1], is a key signalling mediator downstream of integrins, receptor tyrosine kinases and G-protein-coupled receptors (GPCRs) [2-5]. FAK, which controls cell adhesion, polarity, motility, proliferation and survival [6,7], plays a critical role during development and its deletion in mice results in early embryonic death [8-12]. FAK is also involved in human diseases such as cardiac hypertrophy and cancer [13,14]. Increased FAK expression in tumours [7] promotes their progression and metastasis formation [15,14]. FAK activation may also serve as a tumour cell adaptive resistance mechanism [16]. There is therefore considerable interest in targeting FAK with therapeutic agents, inhibitors of FAK kinase activity being currently under investigation in phase I-II clinical trials for various cancers, such as non-small-cell lung cancer, ovarian cancer and mesothelioma $[14,17,16]$. Functional outputs of FAK rely on both kinase-dependent and kinaseindependent functions, on its subcellular localization and on interaction with phospholipids and protein partners $[18,14,19]$. Indeed, in addition to its catalytic properties, FAK is also a scaffolding protein $[18,20,15,19]$ with kinaseindependent functions $[14,21]$.

Subcellular pools of FAK at various places within the cell including the plasma membrane, lamellipodia or the nucleus, are engaged in distinct multimolecular signalling complexes with specific biological functions [22,6]. FAK is also enriched at focal adhesions (FA), which are cellular structures connecting the actin cytoskeleton and the extracellular matrix (ECM), regulating their turnover and integrin-mediated cell adhesion $[23,22,19]$. Molecular mechanisms initiating FAK activation depend on cell context, and remain to be fully characterized in most cases; their identification might provide important new therapeutic avenues.

The main effect attributed to FAK kinase activity is the autophosphorylation of $\mathrm{Tyr}^{397}$, which is positioned between the N-terminal 4.1, ezrin, radixin, moesin (FERM) and the central kinase domains [6]. Phospho-Y397-FAK (pY397-FAK) binds Src-family kinases (SFKs) [5], which mediate most FAK-associated kinase activities including the phosphorylation of FAK on $\mathrm{Tyr}^{576 / 577}$ (pY576/577), $\mathrm{Tyr}^{861}$ (pY861) and $\mathrm{Tyr}^{925}$ (pY925) which are important for FAK catalytic activity, for interaction with signalling partners and for the subcellular localization of FAK [24,5]. In the cytoplasm of quiescent cells, intramolecular interaction between FERM and kinase domains prevents Tyr $^{397}$ accessibility and blocks the catalytic site maintaining FAK in the inactive state [25-28]. Plasma membrane recruitment, which involves the FERM domain, is most often required for FAK activation, FAK dimerization also being important for its autophosphorylation [29]. However, the molecular mechanisms triggering release of constitutive FAK auto-inhibition remain incompletely understood $[18,19]$.

FAK is activated in response to several GPCR ligands [3,4] such as vasopressin [30], angiotensin II (AngII) [31] and gastrin [32] which also elicit FA formation in smooth muscle and colon carcinoma cells respectively [33,34]. Several heterotrimeric G proteins, can mediate FAK activation [35,3,34] which in turn promote cell proliferation, migration and tumour progression downstream of activated GPCRs [3,36,34]. So far, however, the molecular mechanisms leading to FAK activation by G proteins downstream of stimulated GPCRs has remained elusive.

$\beta$-arrestin 1 and 2 ( $\beta$-arr1 and $\beta$-arr2) are ubiquitous proteins that were originally identified as negative regulators of GPCR function [37]. Indeed, $\beta$-arrs uncouple receptors from cognate $G$ proteins and mediate their endocytosis, by bridging GPCRs with clathrin and the adaptor protein AP-2 [38,39]. Through their scaffolding properties $\beta$-arrs also control a broad range of cellular functions, including cytoskeletal rearrangement, cell proliferation, polarity, motility and apoptosis [40-42], which are also regulated by FAK [6,7]. $\beta$-arrs were also suggested to regulate cell spreading and FA dynamics [43]. Thus FAK and $\beta$-arrs can be activated by the same 
receptors, operate in the same subcellular compartments and share signalling partners, such as Src-family kinases, PI3-Kinases and PTEN phosphatase $[44,18,45,6,46,19]$. In the present work, we have identified a direct FAK- $\beta$-arr interaction and have investigated the cross-talk between FAK and $\beta$-arrs. We report that $\beta$-arrs regulate both basal and GPCR-stimulated FAK activity. In absence of stimulation $\beta$-arrs interact with FAK in the cytoplasm, preventing its autophosphorylation, maintaining the kinase inactive and negatively regulating FA number. Following GPCR activation however, the $\beta$-arr/FAK complex is recruited to stimulated receptors at the plasma membrane. Subsequently, $\beta$-arrs interaction with AP-2 releases FAK from $\beta$-arrs enabling G-protein-dependent activation of FAK. 


\section{MATERIALS AND METHODS}

\section{Reagents and antibodies}

AngII and Arginine vasopressin (AVP) were from Sigma. Barbadin (IUPAC: 3-amino-5-(4-benzylphenyl)-3H,4Hthieno[2,3-d]pyrimidin-4-one, Life Chemicals, F0745-0322) was solubilized in 100\% DMSO. All assays using Barbadin were carried out using tips and plates coated with Sigmacote. Antibodies used were: anti-pY397 FAK (clone EP21060Y), anti-FAK (Clone 4.47) from Millipore; anti-FAK (C20) from Santa Cruz; anti- $\beta$-arrestin1/2 (D2H49), anti- $\beta$-arrestin2 (C16D9), anti-Rabbit (DA1E) IgG, anti-pY118-paxillin, anti HA (C29F4), anti-pY397 FAK, antipY576/577 FAK, anti-pY925 FAK from Cell Signaling Technology; anti-HA (3F10), anti-Myc (9E10) and anti-GFP from Roche; anti-Paxillin (clone 349) from BD Biosciences; anti-Vinculin from Sigma; anti- $\beta$-arrestin1 (E274) from Abcam and anti-pY861 FAK (26H16L4) from Invitrogen.

\section{Plasmids}

Myc- $\beta$-arr1/2 [47], GST- $\beta$-arr1/2, Flag- $\beta$-arr1/2, His 6 -TAT-HA- $\beta$-arr2 [45], $\beta$-arr1/2-GFP [48], $\beta$-arr2 $\Delta$ AP-2-GFP, GFP- $\beta$-arr2-C1, GFP- $\beta$-arr2-C1 ( $\triangle$ AP-2 $\Delta$ clat) [49], $\beta$-arr1/2-GFP10, [50], His 6 -TAT-HA-FLNA(23-24) [51], YFPAP2 [52], $\beta$-arr2-Rluc [53] and GFP10- $\beta$-arr2-RlucII [54] constructs were described previously. SNAP-Flag-V2R [55] was a gift from Dr. R. Jockers (Institut Cochin, Paris) and Thomas Roux (Cisbio, France), HA-AT ${ }_{1 A} R$ and Flag$\mathrm{AT}_{1 \mathrm{~A}} \mathrm{R}$-RlucII plasmids [56] were gifts from M.G. Caron (Duke University, USA) and S.A. Laporte (McGill University, Canada), respectively. FAK-pCMV2, FAK-Nter-pCMV2 and GFP-FAK vectors were provided by Dr J-A Girault (UMR-S839, France). RlucII-FAK was generated by subcloning RlucII cDNA upstream of rat FAK in pCMV2 (AgeI-KpnI). HA-FAK and HA-FAK truncations were generated by introducing the HA-Tag 5' to the corresponding FAK-derived sequence in pCMV or pCMV2 vectors. FAK-RlucII was constructed by exchanging GFP10 and FAK cDNA in the pcDNA3.1-GFP10-RlucII plasmid (Nhe1-Kpn1). PCR-generated FAK, FAK-Nter(1402), FAK- $\Delta$ Nter(403-1055) were cloned downstream of the Gal4 transactivation domain in pGAD-GE to generate Gal4AD-FAK, Gal4AD-FAK-Nter and Gal4AD-FAK- $\Delta$ Nter plasmids. Gal4BD- $\beta$-arr2 was constructed by subcloning rat $\beta$-arr2 cDNA into pGBT9 (EcoRV-Sal1). Human $\beta$-arr2 $\Delta$ AP-2-GFP10 and mCherry- $\beta$-arr2 $\Delta$ AP-2 ( $\beta$-arr2-R395A), HA-DRY/AAY-AT ${ }_{1 \mathrm{~A}} \mathrm{R}$ [57] and RlucII-FAKY397F were generated by site-directed mutagenesis (Stratagene). Details of all primers used are provided in Supplementary Table 1.

\section{Cell culture and Transfections}

HEK-293, HEK-AT ${ }_{1 \mathrm{~A}} \mathrm{R}$ [58], HEK-V2R [59] cells and wild-type and $\beta$-arr1/2/- (DKO) MEFs were maintained in

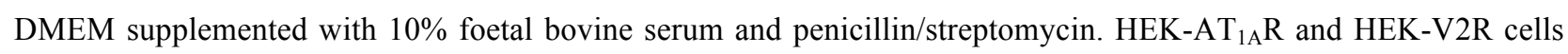
were supplemented with $0.2 \mathrm{mg} / \mathrm{ml}$ Geneticin. HEK-derived cell lines were transfected using Genejuice (Novagen), MEF cell lines using Fugene HD (Promega). On-TARGET plus Smartpool siRNAs from Dharmacon were used to individually target $\beta$-arr1 (L-011971) or $\beta$-arr2 (L-007292), the 5'-ACCUGCGCCUUCCGCUAUG-3' siRNA to target both $\beta$-arrs simultaneously [60]. A Non-targeting pool (D-001810-10-20) or the 5'UAGCGACUAAACACAUCAA-3' sequence were used as control. 60-70\% confluent cells were transfected with the indicated siRNAs at a final concentration of 250nM using DharmaFECT1 (Thermo Scientific). 


\section{Immunocytochemistry}

MEF cells seeded on Labtek chamber slides (ThermoScientific) and siRNA treated HEK-AT ${ }_{1 \mathrm{~A}} \mathrm{R}$ cells seeded on collagen-coated $12 \mathrm{~mm}$ coverslips were fixed with 4\% PFA in PBS for 20min, permeabilized with $0.2 \%$ triton-X-100 in PBS for $5 \mathrm{~min}$ and incubated with blocking buffer (PBS/5\% BSA) for $60 \mathrm{~min}$ at room temperature (RT). Primaryantibody incubation was performed overnight at $4^{\circ} \mathrm{C}$ (pY397-FAK 1:150, Paxillin 1:300, Vinculin 1:300) in blocking buffer. Samples were incubated with appropriate Alexa fluor-conjugated IgG $(\mathrm{H}+\mathrm{L})$ antibodies (1:500) (Invitrogen) for $60 \mathrm{~min}$ at RT and mounted using Prolong-Antifade Mounting medium containing DAPI (Invitrogen). Images were acquired using an inverted Leica spinning-disk microscope (x63 objective) with a CoolSnap HQ2 (Photometrics) CCD camera controlled by Metamorph 7 software. For live cell imaging, HEK-293 cells were seeded on 35mm glass bottom dishes (Ibidi) and transfected with $\mathrm{HA}_{-\mathrm{AT}}{ }_{1 \mathrm{~A}} \mathrm{R}, \mathrm{GFP}-\mathrm{FAK}$ and mCherry- $\beta$-arr $2 \Delta \mathrm{AP}-2$ for $24 \mathrm{hr}$. Samples $(60 \%$ confluent) were washed once with DMEM without phenol red and imaged in the same buffer. The stage of the inverted Leica spinning disk microscope was kept at $37^{\circ} \mathrm{C}$ during the experiment and images acquired at $\mathrm{x} 40$. Samples were visualized using laser excitation at 491 and $561 \mathrm{~nm}$, and emission filters set at 506-545nm for GFP and 573-637nm for mCherry. Representative images were prepared using ImageJ (http://rsb.info.nih.gov/ij/). Icy Bioimaging software was utilized to quantify focal adhesion number and fluorescence intensity. The pY397-FAK/paxillin images were analyzed using the Spot detector plugin [61] set to threshold and filter FA of a minimum size of $5 \mu \mathrm{m}(25$ pixels) to quantify the number and fluorescence intensity of FA per cell.

\section{Western blotting and co-immunoprecipitation}

Samples were lysed at $4^{\circ} \mathrm{C}$ with ice-cold lysis buffer (ICLB), as described [8], and protein concentration determined using Pierce BCA protein assay kit. For western blotting, 30-100 $\mu \mathrm{g}$ of proteins was used. For immunoprecipitations $(500 \mu \mathrm{g}$ proteins) and co-immunoprecipitations (1-1.2 $\mathrm{mg}$ protein for cells, $9 \mathrm{mg}$ for rat brain), lysates were precleared with Protein A/G Plus agarose beads (PA/GPAB, Santa Cruz Biotechnology) and incubated with appropriate antibodies overnight at $4^{\circ} \mathrm{C}$. Immunoprecipitated proteins (IP) were collected with PA/GPAB, washed five times with ICLB and eluted in Laemmli Buffer for the experiments using cell lysates. For the co-immunoprecipitation experiments from brain lysates, the immunoprecipitated proteins were collected with PA/GPAB, washed once with ICLB containing $300 \mathrm{mM} \mathrm{NaCl}$ and once with ICLB $(150 \mathrm{mM} \mathrm{NaCl})$ before being eluted in Laemmli Buffer. Lysates or IP were resolved using SDS-PAGE gels, blotted on nitrocellulose membranes and incubated with appropriate antibodies $(1: 1000)$ overnight at $4^{\circ} \mathrm{C}$. Samples were revealed by enhanced chemiluminescent detection system (ECL, Thermo Scientific) after incubation with HRP-conjugated secondary antibodies (Jackson ImmunoResearch) and visualized using a chemiluminescent reader LAS-3000 (Fuji Lifesciences). Quantification was performed using Image $\mathrm{J}$ (http://rsb.info.nih.gov/ij/).

\section{GST pull down}

Freshly prepared recombinant GST, GST- $\beta$-arr1 and GST- $\beta$-arr2 proteins $[62,45,51]$ bound on Glutathione

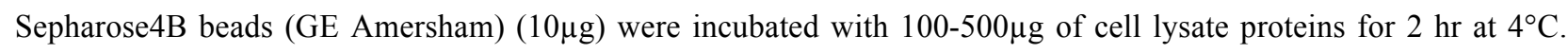
The beads were washed three times with ice-cold lysis buffer [8] containing 300mM NaCl, two times with ICLB and resuspended in Laemmli Buffer before SDS-PAGE. 


\section{Kinase assay}

Recombinant His $_{6}$-TAT-HA- $\beta$-arr2 or His $_{6}$-TAT-HA-FLNA(23-24) proteins were prepared as above. The kinase assays were performed in kinase buffer containing $20 \mathrm{mM}$ Tris-Base $\mathrm{pH} 7.5,150 \mathrm{mM} \mathrm{NaCl}, 25 \mathrm{mM} \mathrm{MgCl}_{2}, 5 \mathrm{mM}$ $\mathrm{MnCl}_{2}, 1 \mathrm{mM} \mathrm{Na} \mathrm{VO}_{4}$ and $5 \mathrm{mM} \beta$-mercaptoethanol. GST-FAK (Active Motif) was incubated on ice for $10 \mathrm{~min}$ with either PBS (ctrl) or increasing amount of His $_{6}$-TAT-HA- $\beta$-arr2 corresponding to molar $\beta$-arr2/FAK ratio of 0.5 ; 1.3 and 3.3 (Supplementary Fig. 2a) or with a molar $\beta$-arr2/FAK and FLNA(23-24)/FAK ratio of 3.3 (Fig. 3a). An aliquot was taken from the reaction Mix (0) when $100 \mu \mathrm{M}$ ATP (Abcam) was added to initiate the assay, which was performed at $30^{\circ} \mathrm{C}$ for another $10 \mathrm{~min}$. 2x Laemmeli Buffer was added to terminate the reaction and samples processed by SDS-PAGE. Each single time point monitored the autophosphorylation of $50 \mathrm{ng}(0,344$ pmoles $)$ of GSTFAK in a $10 \mu 1$ volume.

\section{Yeast two-hybrid assay}

The assay was performed using the HF7c yeast reporter strain as described [62].

\section{BRET}

BRET is a proximity assay for proteins situated at a respective distance of 10nM or less. Two proteins of interest are fused to the BRET donor, a luciferase, or to the BRET acceptor, a fluorescent protein. Upon addition of the luciferase substrate, the non-radiative energy emitted by the enzyme is transferred to the fluorescent protein, which emits fluorescence at a specific wavelength. BRET-1 experiments were conducted with the Renilla luciferase (Rluc) and the yellow fluorescence protein (YFP) as BRET donor and acceptor, using coelenterazine $\mathrm{h}$ as substrate. In BRET-2 experiments an optimized version of the luciferase (RlucII) and of the GFP (GFP10) fluorescent proteins were used in the presence of Coelenterazine 400a as substrate. BRET saturation assays were performed as described [62]. Briefly, HEK-293 cells transfected with a constant amount of RlucII-FAK (BRET donor) plasmid and increasing amounts of $\beta$-arr1/2-GFP10 (BRET acceptor) plasmid were seeded on poly-ornithine $(30 \mu \mathrm{g} / \mathrm{ml})$ coated white 96 -well optiplates (Perkin Elmer) at a density of 20,000 cells per well $24 \mathrm{hr}$ post-transfection. The next day, BRET readings were performed in HBSS buffer using the Mithras LB 940 (Berthold Technologies). GFP-10-associated fluorescence was first measured to quantify in each well the amount of BRET acceptor in each well; after the addition of the luciferase substrate Coelenterazine 400a (Interchim, $2.5 \mu \mathrm{M}$ final) both RlucII (410nm) and GFP10 (515nm) signals were measured simultaneously. BRET signal is the ratio of light emitted at $515 \mathrm{~nm}$ over the light emitted at $410 \mathrm{~nm}$. Values are means \pm s.e.m. of three independent experiments. Saturation curves were plotted as described [62] using GraphPad Prism. Single point BRET experiments (using RlucII-FAK/ $\beta$-arr2-GFP10 or $\beta$-arr2-Rluc/YFP-AP2) were conducted to monitor the effects of AngII or AVP stimulation over time. In these experiments HEK-293 cells were co-transfected with the appropriate receptor plasmids $\left(\mathrm{HA}-\mathrm{AT}_{1 \mathrm{~A}} \mathrm{R}\right.$ or SNAP-V2R-Flag) and serum-starved for 6 hours in DMEM before stimulation. AngII or AVP were added for the indicated time at $37^{\circ} \mathrm{C}$ and BRET measurements were performed immediately as described above. In BRET 1 experiments (using $\beta$-arr2-Rluc/YFP-AP2 as donor and acceptor respectively) YFP-associated fluorescence was first measured; then after the addition of Coelenterazine $h$ (Interchim, $5 \mu \mathrm{M}$ final) both Rluc (485 nm) and YFP (530 nm) signals were measured simultaneously. The BRET ratio signal is the ratio of light emitted at $530 \mathrm{~nm}$ over the light emitted at $485 \mathrm{~nm}$. Values are means \pm s.e.m. of three independent experiments. Inverse BRET is described in the Supplemental Methods section. 


\section{Statistical Analyses}

Data are mean \pm s.e.m. Statistical analyses were performed using Graphpad Prism with either unpaired two-tailed Student's t-test or ANOVA with Bonferroni Post hoc tests for significance comparison as appropriate. Data was considered significant when $(*)$ : $\mathrm{P}$ value $<0.05,(* *)$ : $\mathrm{P}$ value $<0.01,(* * *)$ : $\mathrm{P}$ value $<0.001$ and $(* * * *)$ : $\mathrm{P}$ value $<0.0001$ respectively. 


\section{Results}

\section{pY397-FAK is enhanced in $\beta$-arr deficient cells}

Comparison of FAK autophosphorylation on $\mathrm{Tyr}^{397}$ in serum-deprived wild-type (wt) and $\beta$-arr1/2 knock-out (DKO) mouse embryonic fibroblasts (MEFs) [63], showed an increase in basal autophosphorylated FAK (pY397-FAK) in cells lacking $\beta$-arrs (Fig. 1a). FAK autophosphorylation returned to a level close to that observed in wt-MEFs upon expression of Flag-tagged $\beta$-arr1 or $\beta$-arr2 (Supplementary Fig. 1a) suggesting that $\beta$-arrs downregulate FAK autophosphorylation. Since the tyrosine kinase Src binds to pY397-FAK and then phosphorylates FAK on Tyr ${ }^{576 / 577}$, $\mathrm{Tyr}^{861}$ and $\mathrm{Tyr}^{925}$, we also compared the phosphorylation of these specific residues in wt and DKO cells (Supplementary Fig. 1b). In DKO MEFs the phosphorylation of $\mathrm{Tyr}^{576 / 577}$ and $\mathrm{Tyr}^{925}$ was increased compared to wt cells, similarly to that of $\mathrm{Tyr}^{397}$, whereas the phosphorylation of $\mathrm{Tyr}^{861}$ was unchanged.

Since $\beta$-arrs were reported to control cell spreading [43] and proteins implicated in cell adhesion [64], we examined whether enhanced FAK autophosphorylation might also occur in DKO MEFs held in suspension. Because FAK basal autophosphorylation is markedly decreased in suspended cells, FAK was immunoprecipitated from lysates of serumdeprived cells in suspension to enrich the signal (Fig. 1b). Again basal pY397-FAK was increased in DKO compared to wt-MEFs. These results indicate that $\beta$-arrs inhibit basal FAK autophosphorylation independently of extracellular stimuli, in both non-adherent and adherent MEFs. Paxillin, a FAK-interacting protein localized to focal adhesions (FA), and pY397-FAK were co-localized in FA of wt and DKO MEFs (Fig. 1c); Paxillin and pY397-FAK-containing FA were 3 times more abundant in DKO than in wt MEFs, the average intensity of pY397-FAK labelling in FA being markedly enhanced in the absence of $\beta$-arrs (Fig. 1d-f). These observations support the hypothesis that $\beta$-arrs maintain a low basal pY397-FAK in MEFs and negatively regulate FA number.

\section{FAK and $\beta$-arrestins are interacting partners}

We next examined whether $\beta$-arrs and FAK might associate in the same molecular complex. Co-immunoprecipitation experiments from lysates of transfected HEK-293 cells, showed that HA-FAK co-immunoprecipitated GFP-tagged $\beta$-arr1 or $\beta$-arr2 (Fig. 2a) and, conversely, that both Myc-tagged $\beta$-arrs co-immunoprecipitated HA-FAK (Fig. 2b). These results confirm recent data showing that FAK and $\beta$-arr1 can be found in the same molecular complex [65], and also suggest that $\beta$-arr2 interacts with FAK. We confirmed this observation by showing that FAK and $\beta$-arr2 specifically interact in a two-hybrid assay (Fig. 2c) and that purified recombinant $\beta$-arr1 or $\beta$-arr2 pulled down both transfected HA-FAK and endogenous FAK from lysates of HEK-293 cells (Fig. 2d-e). Importantly, endogenous FAK could also be coimmunoprecipitated with endogenous $\beta$-arrs from rat brain lysate (Fig. 2f). Bioluminescence Resonance Energy Transfer (BRET) saturation experiments [62] were also used to monitor the proximity of these proteins in living cells. A constant amount of a plasmid encoding the fusion protein between FAK and Renilla Luciferase 2 (RlucII, the BRET donor) and increasing amounts of plasmids encoding either $\beta$-arr1 or $\beta$-arr 2 fused upstream of the GFP variant GFP10 (the BRET acceptor), were transfected in HEK-293 cells. Hyperbolic curves, indicative of specific FAK/ $\beta$-arr proximity $(<10 \mathrm{~nm})$ were obtained in attached cells compared to linear bystander non-specific BRET observed with GFP $_{10}$ as control BRET acceptor (Fig. 2g and Supplementary Fig. 2a). In addition, similar BRET50 values were calculated for saturation with $\beta$-arr1 or $\beta$-arr2, indicating that both $\beta$-arr isoforms display a similar propensity to be in close proximity with FAK. Similar results were obtained in cells maintained in suspension prior to BRET measurements (Fig. 2h). The specificity of BRET between FAK and $\beta$-arrs was further 
confirmed by an inverse BRET experiment, in which constant amounts of BRET acceptor were expressed in the presence of increasing concentrations of the BRET donor. Supporting specific interaction, the BRET signal decreased with increasing concentrations of RLucII-FAK (Supplementary Fig. 2b). These data indicate that $\beta$-arrs and FAK interact under basal conditions even in the absence of cell adhesion and that the basal inhibition of FAK autophosphorylation in wt MEFs, compared to $\beta$-arr DKO-MEFs, might be caused by this interaction.

\section{$\beta$-arr inhibits FAK catalytic activity and FA number}

In vitro kinase assays with purified recombinant proteins were performed to investigate the effect of $\beta$-arr2 on FAK autophosphorylation. GST-FAK autophosphorylation was inhibited up to $70 \%$ with His6-HA- $\beta$-arr2 (Fig. 3a) in a dose-dependent manner (Supplementary Fig. 3a). In control experiments, incubation with carboxyterminal regions of filamin A (His6-HA-FLNA 23-24) [51], had no effect on FAK autophosphorylation (Fig. 3a). These results indicate that $\beta$-arr2 interacts directly with FAK and inhibits its autophosphorylation.

Next, we investigated whether the constitutive inhibition exerted by $\beta$-arrs on FAK also affects its stimulation by a GPCR. The amount of either or both $\beta$-arrs was modulated in HEK-AT ${ }_{1 A} \mathrm{R}$ cells, which stably express the angiotensin receptor $\mathrm{AT}_{1 \mathrm{~A}} \mathrm{R}$, using appropriate siRNAs (Supplementary Fig. 3b-c). Under basal conditions, the decrease of either or both isoforms significantly enhanced endogenous pY397-FAK (Fig. 3b), suggesting that both $\beta$-arr1 and $\beta$-arr2 inhibit basal FAK catalytic activity as observed in MEFs (Fig. 1). After a short (2 min) stimulation of HEK-AT ${ }_{1 \mathrm{~A}} \mathrm{R}$ cells with AngII, both pY397-FAK and FAK phosphorylation on Tyr-576/577 were enhanced (Supplementary Fig. 4a). When $\beta$-arr1 and $\beta$-arr2 expression was inhibited independently or simultaneously, the amount of endogenous pY397-FAK observed after 2 min stimulation of the $\mathrm{AT}_{1 \mathrm{~A}} \mathrm{R}$ by AngII was further increased compared to control siRNA-treated cells (Fig. 3b).

Stimulation of $\mathrm{AT}_{1 \mathrm{~A}} \mathrm{R}$ was reported to regulate actin cytoskeleton remodelling [66-68,51]. The activation of $\mathrm{FAK}$ by AngII in HEK-AT ${ }_{1 A} \mathrm{R}$ induced cell spreading and the formation of stress fibres associated with an increased number of FAs where FAK was colocalized with vinculin (Supplementary Fig. 4b). Following down-modulation of $\beta$-arr1, $\beta$-arr2 or both, under basal conditions the number of FA per cell was doubled compared to cells treated with control siRNA and further increased after AngII stimulation (Fig. 3c). These changes reflect both the increase of the number of FAs per cell (Fig. 3d) and the content of pY397-FAK in FAs (Fig. 3e). In conclusion, the above results demonstrate that $\beta$-arr content modulates FAK autophosphorylation and FA number under both basal and stimulated conditions.

\section{FAK $N$-ter is required for $F A K / \beta$-arr interaction and FAK inhibition}

To identify the domain of FAK involved in $\beta$-arr-binding, we used a two-hybrid assay and found that the $\mathrm{N}$-terminal fragment of FAK (Nter, 1-402) (Fig. 4a), which contains the FERM domain, interacted with $\beta$-arr2 (Fig. 4b), whereas the deletion of this fragment (FAK- $\Delta$ Nter, Fig. 4a) resulted in loss of interaction (Fig. 4b). Co-immunoprecipitation experiments comparing $\beta$-arr1 and $\beta$-arr2 confirmed that both isoforms could interact with FAK-Nter (Fig. 4c). In addition, the presence of excess FAK-Nter in a BRET assay using FAK-RLucII as donor at minimal saturating concentration of the BRET acceptor $\beta$-arr2-GFP ${ }_{10}$, decreased the BRET signal by approximately $50 \%$ (Fig. $4 \mathrm{~d}$ ), indicating that the FAK-N-ter fragment competed with the full-length FAK for its interaction with $\beta$-arr2.

Since $\beta$-arrs interact with the N-terminal of FAK, this region should be required for the basal inhibition of FAK autophosphorylation by $\beta$-arrs. To test this hypothesis, HEK-293 cells treated with control siRNA or siRNA targeting 
both $\beta$-arr1 and $\beta$-arr2 were transfected with full length HA-FAK or FAK deleted of residues 1-375 (HA-FAK-(3761055)), and their basal autophosphorylation were monitored after immunoprecipitation (Fig. 4e). In control cells, the autophosphorylation of HA-FAK-(376-1055) was increased compared to HA-FAK, confirming the expected lack of FAK autoinhibition of its catalytic activity, which is normally exerted by the FERM domain [26,69]. Downmodulation of $\beta$-arrs resulted in increased basal pY397-HA-FAK (as shown for endogenous FAK in Fig. 3b), but did not change the autophosphorylation of HA-FAK-(376-1055) indicating that the truncation of residues 1-375, which contain the FERM domain of FAK, renders FAK insensitive to $\beta$-arr basal inhibition in intact cells.

\section{G proteins mediate $F A K$ activation upon $A T_{1 A} R$ stimulation}

Since GPCRs concurrently signal through $\beta$-arrs and activate FAK, we next investigated whether and how the constitutive inhibitory effect of $\beta$-arrs on FAK activity is actually released under conditions of FAK stimulation. Stimulated GPCRs, including the $\mathrm{AT}_{1 \mathrm{~A}} \mathrm{R}$, can elicit signalling pathways through both $\mathrm{G}$ proteins and $\beta$-arrs [70]. The $\mathrm{AT}_{1 \mathrm{~A}} \mathrm{R}$-DRY/AAY receptor mutant lacks functional coupling with $\mathrm{G}$ proteins but maintains $\beta$-arr recruitment and downstream signalling [71,57]. Contrasting with $\mathrm{AT}_{1 \mathrm{~A}} \mathrm{R}$, agonist-activated $\mathrm{AT}_{1 \mathrm{~A}} \mathrm{R}-\mathrm{DRY} / \mathrm{AAY}$ failed to promote endogenous FAK autophosphorylation above basal levels (Fig. 5a) whereas they both promoted the expected comparable recruitment and activation of $\beta$-arrs [57] as shown with GFP $_{10}-\beta$-arr2-RlucII, a BRET-based $\beta$-arr2 translocation biosensor [54] (Fig. 5b). Consistently, the AngII-derived DVG peptide, a $\beta$-arr-biased agonist of the $\mathrm{AT} 1_{1 \mathrm{~A}} \mathrm{R}[56,72]$, failed to stimulate FAK autophosphorylation (Fig. 5c), at a concentration that elicits maximal $\beta$-arr translocation in response to AngII (Fig. 5d) [54]. These data indicate that increased FAK autophosphorylation by AngII requires the activation of G-proteins downstream of the $\mathrm{AT} 1_{1 \mathrm{~A}} \mathrm{R}$.

\section{$\beta$-arr/AP-2 interaction upon AngII stimulation releases FAK}

The potentiation of FAK activation following down-modulation of $\beta$-arrs, under both basal and GPCR-stimulated conditions (Fig. 3) suggests that full GPCR-dependent activation of FAK requires both the role of G proteins and the simultaneous release of the constitutive inhibitory effect of $\beta$-arrs. Co-immunoprecipitation experiments from lysates of HEK-AT ${ }_{1 \mathrm{~A}} \mathrm{R}$ transfected with HA-FAK and GFP- $\beta$-arr2, indeed showed a marked decrease $(50 \%)$ in the amount of FAK co-immunoprecipitated with $\beta$-arr2 upon $\mathrm{AT}_{1 \mathrm{~A}} \mathrm{R}$ stimulation, compared to unstimulated conditions (Fig. 6a), demonstrating that FAK is released from $\beta$-arr2 following AngII treatment. Importantly, no autophosphorylated FAK was contained in the fraction co-immunoprecipitated with $\beta$-arr2 from lysates of both non-stimulated and AngIIstimulated cell lysates (Fig. 6a) and a FAK mutant that cannot autophosphorylate (FAKY397F) showed similar BRET saturation with $\beta$-arr2 than wild-type FAK (Supplementary Fig. 5a), both RlucII-FAK and RlucII-FAK mutant being expressed at a level similar to endogenous FAK (Supplementary Fig. 5b). These results indicate that nonautophosphorylated FAK is maintained inactive by its interaction with $\beta$-arr2 under basal conditions and that the complex dissociates following AngII treatment (Fig. 6a). We then investigated how $\beta$-arr-FAK complex dissociation may occur. BRET experiments were conducted using FAK-RLucII and $\beta$-arr2-GFP ${ }_{10}$ at the minimal saturating concentration of BRET acceptor in HEK-293 cells expressing $\mathrm{AT}_{1 \mathrm{~A}} \mathrm{R}$. Treatment of the cells with AngII induced a reduction of the BRET signal (Fig. 6b) reflecting the release of FAK from its complex with $\beta$-arr2. Upon recruitment to activated GPCRs, the carboxyterminal tail of $\beta$-arr2 is tilted, unmasking binding sites for the $\beta 2$-adaptin subunit of AP-2 and for clathrin allowing $\beta$-arr2 interaction with AP2 [49,73,74]. Accordingly, BRET experiments with $\beta$ arr2- 
Luc and YFP-AP2 showed that the initial increase of FAK autophosphorylation in response to the stimulation of the $\mathrm{AT}_{1 \mathrm{~A}} \mathrm{R}$, which peaks at 2-5 min (Supplementary Fig. 4, Fig. 6e, Fig. 7b), coincides with an increased interaction between $\beta$-arr2 and AP-2 (Supplementary Fig. 6). To examine whether the agonist-promoted dissociation of the FAK$\beta$-arr2 complex could be functionally connected with $\beta$-arr2/AP-2 interaction, we took advantage of a $\beta$-arr2 mutant $(\beta$-arr2 $\triangle \mathrm{AP}-2)$ with an Alanine substitution of the Arginine-395 that blocks its interaction with $\beta 2$-adaptin but not recruitment to GPCRs $[49,74,75]$. BRET experiments showed that $\beta$-arr2 $\triangle A P-2$ interacted with FAK similarly to the wt $\beta$-arr2 under basal conditions (Fig. $6 \mathrm{~b}$ and Supplementary Fig. 7a) and that $\beta$-arr2 $\Delta$ AP-2 was recruited to the AT1AR like the wt $\beta$-arr2 upon Ang II treatment (Supplementary Fig. 7b). Live immunofluorescence confocal microscopy of HEK-293 cells transfected with GFP-FAK and mCherry- $\beta$-arr2 $\triangle$ AP-2 (Fig. $6 c$ ) further indicated that FAK and $\beta$-arr2 $\triangle \mathrm{AP}-2$ were expressed diffusely in the cytoplasm in absence of stimulation, and that they accumulated simultaneously at the plasma membrane, where they were co-localized following AngII treatment (Fig. 6c). We next compared FAK release and activation in the presence of $\beta$-arr2 $\triangle \mathrm{AP}-2$ or wt $\beta$-arr2. Although the basal BRET measured with FAK and $\beta$-arr2 $\triangle \mathrm{AP}-2$ constructs was unchanged, stimulation with AngII failed to induce the same BRET change observed with wt $\beta$-arr2 (Fig. 6b). A plausible interpretation of these findings is that the interaction of $\beta$-arr2 with AP-2, after the translocation of the $\beta$-arr2/FAK complex to activated receptors, would produce a conformational change in the complex, which would release FAK from $\beta$-arr2. To validate this hypothesis, coimmunoprecipitation experiments were performed using lysates of control or AngII-stimulated HEK-AT $T_{1 A} R$ cells expressing HA-FAK and $\beta$-arr2-GFP or $\beta$-arr2 $\triangle$ AP-2-GFP. Compared to basal conditions, stimulation of the $\mathrm{AT}_{1 \mathrm{~A}} \mathrm{R}$ did not change the amount of FAK, which was co-immunoprecipitated with $\beta$-arr2 $\Delta \mathrm{AP}-2$ as opposed to the marked decrease of FAK co-immunoprecipitated with wild type $\beta$-arr2 (Fig. 6d). These results support the hypothesis that the interaction of $\beta$-arr2 with AP-2 induces the dissociation of the $\beta$-arr2/FAK complex and the release of FAK after AngII treatment. We next examined whether the release of FAK from $\beta$-arr2, consequently to its interaction with AP2 , would also relieve the constitutive inhibition of $\beta$-arr2 on FAK. FAK autophosphorylation was monitored in HEK$\mathrm{AT}_{1 \mathrm{~A}} \mathrm{R}$ expressing comparable levels of $\beta$-arr2-GFP or $\beta$-arr2 $\triangle \mathrm{AP}-2$-GFP (Fig. 6e). Agonist-promoted endogenous FAK autophosphorylation was markedly decreased $(>50 \%)$ at all time points in cells expressing $\beta$-arr2 $\triangle \mathrm{AP}-2$-GFP, compared to cells containing $\beta$-arr2-GFP. Moreover, Barbadin ( $\beta$-arrestin/ $\beta 2$-adaptin interaction inhibitor), a recently characterized small molecule, which inhibits GPCR endocytosis by specifically blocking the interaction of $\beta$-arrs with AP-2 [76], abolished the AngII-promoted BRET change, without affecting basal BRET (Fig. 7a and Supplementary Fig. 8a-b). Consistent with our hypothesis and recapitulating the effect observed in cells expressing $\beta$-arr2 $\Delta$ AP-2 (Fig. 6e), preincubation with Barbadin markedly decreased the level of endogenous FAK autophosphorylation induced by $\mathrm{AT}_{1 \mathrm{~A}} \mathrm{R}$ stimulation (Fig. 7b). To determine whether the interaction between $\beta$-arr and AP-2 regulates FAK activation downstream of additional GPCRs, we performed similar experiments in HEK-293 cells stably expressing the V2 vasopressin receptor (HEK-V2R). Vasopressin (AVP) induced a strong autophosphorylation of FAK in these cells with a peak between 2 and $5 \mathrm{~min}$ (Fig. 7c) that was correlated with an increased $\beta$-arr2/AP-2 interaction (Supplementary Fig. 6) similarly to what was observed in response to AngII stimulation (Fig. 4, Fig. 6e, Fig. 7b and Supplementary Fig. 6). Barbadin strongly inhibited too the endogenous activation of FAK in response to AVP treatment in HEK-V2R (Fig. 7c). Thus, the role of $\beta$-arr and of its interaction with AP-2 in the activation of FAK is not limited to the $\mathrm{AT}_{1 \mathrm{~A}} \mathrm{R}$. Noteworthy, 15 min after stimulation, $\mathrm{FAK}$ autophosphorylation was still sustained in response to AngII, whereas it markedly decreased in response to AVP (Fig. 7b-c). To determine whether this 
difference in the kinetic of FAK dephosphorylation was correlated with the interaction between FAK and $\beta$-arr, we compared co-immunoprecipitation between $\beta$-arr2 and FAK in HEK-AT ${ }_{1 A} \mathrm{R}$ and HEK-V2R cells after 15 min of receptor stimulation. In co-immunoprecipitation experiments from AngII-stimulated HEK-AT ${ }_{1 \mathrm{~A}} \mathrm{R}$ cell lysates the amount of FAK co-immunoprecipitated with $\beta$-arr2 remained markedly decreased compared to unstimulated conditions (Supplementary Fig. 9a) reflecting FAK release from $\beta$-arr2. Under the same conditions, the amount of FAK co-immunprecipitated with $\beta$-arr2 from AVP-stimulated HEK-V2R cell lysates, was comparable to that obtained in basal conditions (Supplementary Fig. 9b). These results confirm that the level of FAK autophosphorylation is correlated to its interaction with $\beta$-arr. Phosphorylation of paxillin downstream of activated FAK mediates the reorganization of the cytoskeleton, FAs turnover and cell movement [77]. To further demonstrate that the regulation of FAK by $\beta$-arrs impacts important downstream signalling, we determined paxillin phosphorylation in response to $\mathrm{AT}_{1 \mathrm{~A}} \mathrm{R}$ stimulation. Similarly to pY397-FAK, paxillin phosphorylation was markedly decreased in cells expressing $\beta$-arr2 $\Delta$ AP-2 (Fig. 6e) or preincubated with Barbadin (Fig. 7b). Similar and even larger effects were also observed in HEK-V2R cells pretreated with Barbadin (Fig. 7c). These results demonstrate that the regulation of FAK by $\beta$-arrs has important downstream signalling effects in cells.

Saturation of coated pit-associated AP-2 and clathrin with the C-terminal tail of $\beta$-arr2 (amino acids 317-410; C1), inhibits $\beta$-arr interaction with AP-2 and GPCR endocytosis [49]. Endogenous FAK autophosphorylation in response to AngII treatment was decreased by $50 \%$ in cells expressing this $\mathrm{C} 1$ peptide fused to GFP (GFP-C1), compared to GFP-transfected cells, indicating a dominant negative effect on FAK activation. Mutation of the AP-2 and clathrin binding sites within the $\mathrm{C} 1$ sequence (GFP-C1mut) restored the level of pY397-FAK to that observed in cells expressing GFP, indicating that binding to AP-2 and clathrin is essential for GFP-C1 dominant negative effect (Supplementary Fig. 10).

Taken together, our data indicate that the GPCR-dependent activation of FAK in complex with $\beta$-arrs at steady state results from the synergistic termination of the constitutive inhibition exerted by $\beta$-arrs and the G-protein-dependent activation of FAK released from the complex with $\beta$-arrs. 


\section{DISCUSSION}

We report that $\beta$-arrs are essential regulators of FAK activity under both basal and GPCR-stimulated conditions. We uncovered a mechanism whereby $\beta$-arrs appear to play a dual role in the regulation of FAK activation: they inhibit FAK autophosphorylation under basal conditions while promoting localized FAK activation by G proteins through their recruitment to activated receptors (Fig. 8).

In the cytoplasm of resting cells $\beta$-arrs are associated with FAK. The observation of increased basal FAK autophoshorylation in cells with no or reduced expression of $\beta$-arrs, together with the observation that only nonautophosphorylated FAK interacts with $\beta$-arr2, support a model where the constitutive association of these proteins maintains FAK inactive and prevents its autophosphorylation (Fig. 8). This model is also supported by the direct inhibition of FAK catalytic activity by $\beta$-arr2 in vitro.

Our data reveal an unknown role for $\beta$-arrs as FAK inhibitors. In non-stimulated cells, cytoplasmic FAK is maintained inactive by intra-molecular contacts between the FERM and the catalytic domains [25-28]. We found that the FAK Nterminus, which contains the FERM domain, is sufficient for the association with $\beta$-arr and necessary for the $\beta$-arrdependent basal inhibition of FAK. Under basal conditions $\beta$-arrs could stabilize the interaction between FERM and kinase domains preventing FAK "opening" (Fig. 8). Bound $\beta$-arrs may also mask Tyr ${ }^{397}$, which is involved in the initial activation of FAK (Fig. 8). FIP200, another FAK protein inhibitor [78], acts differently from $\beta$-arr since it binds directly to the kinase domain of FAK [79].

We showed that GPCR-dependent activation of FAK is controlled by an ordered sequence of events that depends on both $\beta$-arr and $G$ protein activation. We found that $\beta$-arr and FAK translocate simultaneously to the plasma membrane where they co-localize upon AngII treatment. The translocation of the $\beta$-arr/FAK complex to activated receptors promotes the interaction between $\beta$-arr and AP-2. This contact releases FAK from $\beta$-arrs and enables its activation by proximal receptor-stimulated G proteins (Fig. 8). The functional significance of this regulation is demonstrated by the downstream effect on paxillin phosphorylation. Thus we have identified an essential role of $\beta$-arrs in which the interaction of $\beta$-arrs with AP- 2 is involved in the release of an inhibitory control mode of $\beta$-arrs over a downstream effector system. Our study also deciphers the respective contribution of $\beta$-arrs and G proteins to FAK activation and the delineation of the molecular mechanism of their coordinated action involving AP-2.

Reported models of FAK activation and stress fibres and/or FA formation downstream of GPCRs involve RhoA GTPases [66-68,33] and potential cross-talk between RhoA and $\beta$-arrs has also been documented in different contexts $[66,45,80]$. For example, RhoA participates in the $\beta$-arr-dependent regulation of PTEN downstream of the lysophosphatidic acid receptor $[45,80]$. The Rho exchange factor Rgnef and $\mathrm{G} \alpha_{13}$ also concur to recruit and activate FAK at the plasma membrane, downstream of CCK2 receptors [32]. FAK clustering was proposed to contribute to its activation $[18,14,19]$; $\beta$-arrs might thus also promote its autophosphorylation, by accumulating FAK in proximity to activated GPCRs. FAK activation requires both the release of the autoinhibition exerted by the FERM domain and the trans-phosphosphorylation by nearby FAK catalytic domains [19]. Both events can be achieved via the FERM domain-dependent recruitment of FAK to $\beta$-integrins, growth-factor receptors and/or plasma membrane-associated lipids $[18,14,19]$. In this context, $\beta$-arrs, by forming a bridge between the FERM domain and the activated $\mathrm{AT}_{1 \mathrm{~A}} \mathrm{R}$, might also contribute to increase proximal local concentrations of FAK thus promoting subsequent transphosphorylation. 
FAK is regulated by several GPCRs and most activated GPCRs recruit $\beta$-arrs. In the present study we report that the $\beta$-arr2-mediated control of FAK activity is modulated by both the $\mathrm{AT}_{1 \mathrm{~A}} \mathrm{R}$ and the V2R. It appears that, whereas the activation rate of FAK autophosphorylation by these receptors is similar, the duration of FAK activation may vary depending of the receptor since FAK autophosphorylation was sustained in response to AngII but more transient in response to AVP, this difference being correlated to the amount of $\beta$-arr2 bound to FAK in each case. Multiple mechanisms might be involved in this phenomenon, such as the duration of G-protein coupling with the receptor, which depends on desensitization mechanisms, or the specific $\mathrm{G}$ protein the receptors are preferentially coupled to. Whereas V2R is principally coupled to Gs, $\mathrm{AT}_{1 \mathrm{~A}} \mathrm{R}$ is coupled to $\mathrm{Gq}$; downstream effectors of either $\mathrm{G}$ protein might contribute to FAK re-association with $\beta$-arrs. Specific investigations will be required to address this issue. Other GPCRs might also activate FAK in a $\beta$-arr-dependent manner. Indeed a $\beta$-arr1/STAM1 (Signal-transducing Adaptor Molecule 1) complex was recently found to modulate FAK downstream of the GPCR CXCR4 [65]. On the other hand $\beta$-arr-dependent FAK regulation could also occur downstream of integrins, since $\beta$-arrs interact with filamin, an integrin-binding protein, to regulate cytoskeleton remodelling [51].

We found that Barbadin, a newly identified AP-2 binding small molecule that prevents $\beta$-arrestin interaction with AP2 without interfering with its recruitment to activated GPCRs [76] inhibits FAK activation. Barbadin may therefore represent an interesting tool for the development of FAK inhibitors downstream of GPCRs.

Src recruited to pY397 can phosphorylate FAK on $\mathrm{Tyr}^{576}, \mathrm{Tyr}^{577}, \mathrm{Tyr}^{861}$ and $\mathrm{Tyr}^{925}$. As expected the absence of $\beta$-arrs in DKO MEFs, which results in increased pY397, also promotes phosphorylation of Tyr ${ }^{576 / 577}{\operatorname{and~} \mathrm{Tyr}^{925} \text {. Tyr }}^{576 / 577} \operatorname{are}^{9}$ located in the central kinase domain of FAK and their phosphorylation is required for full catalytic activity of FAK whereas pY925 acts as a docking site for growth-factor-receptor-bound protein 2 (Grb2), which permits signalling to the Ras-ERK cascade and regulates FAK localization at FA [24,5]. The phosphorylation of Tyr ${ }^{861}$, which may have multiple functions and has mostly been characterized as an important regulator of angiogenic response, is unchanged in DKO MEFs compared to wt-MEFs. Alternative mechanisms of $\mathrm{Tyr}^{861}$ phosphorylation have been suggested. One of these mechanisms would require Src-SH2 domain (that binds to pY397) but not Src enzymatic activity, suggesting that Src bound to pY397 may bridge FAK with another kinase phosphorylating Tyr ${ }^{861}$ [81]. Other studies reported that phosphorylation of $\mathrm{Tyr}^{861}$ can be uncoupled from the one of $\operatorname{Tyr}^{397}$ [82-86]. Our results suggest that none of the above mechanisms are regulated by $\beta$-arrs in MEFs since the phosphorylation of $\mathrm{Tyr}^{861}$ is unchanged in DKO compared to wt-MEFs. Thus through the regulation of $\mathrm{Tyr}^{397}$ phosphorylation, $\beta$-arrs also regulate the phosphorylation of $\mathrm{Tyr}^{576 / 577}$ and $\mathrm{Tyr}^{925}$ but not $\mathrm{Tyr}^{861}$.

Ang II promotes the formation of stress fibres and FAs $[66,67,33]$ and FAK plays an important role in the turnover of FAs [6]. Here, FAK regulation via $\beta$-arrs was correlated with FAK autophosphorylation, paxillin phosphorylation and FA number in resting and AngII-stimulated cells, extending the spectrum of $\beta$-arr impact on cytoskeletal reorganization. $\beta$-arrs were reported to promote FA disassembly independently of receptor activation [43] and the $\beta 2$ adrenergic receptor-dependent regulation of FA, involves RhoA and the $\beta$-arr2-dependent regulation of its upstream activator p115-RhoGEF [87]. Our results suggest that FAK activation and FA formation require both the initial translocation of the FAK- $\beta$-arr complex to the activated receptor and subsequent $\beta$-arr interaction with AP-2. Although several different mechanisms involving $\beta$-arrs and/or FAK likely converge to regulate FA formation, the control of plasma membrane targeting and activation of protein partners involved in this process by $\beta$-arrs may be particularly important. 
Both $\beta$-arr isoforms interact with FAK, and $\mathrm{BRET}_{50}$ values, which reflect the apparent propensity of association with FAK in intact cells, were similar for $\beta$-arr1 and $\beta$-arr2. In addition, introduction of $\beta$-arr1 or $\beta$-arr2 in DKO MEFs resulted in pY397-FAK returning to the level observed in wt-MEFs and siRNA-mediated knock-down of either $\beta$-arr in HEK caused the same effect on FAK autophosphorylation. Thus, both $\beta$-arrs appear to contribute to FAK inhibition, a global decrease of $\beta$-arr level below a certain threshold being sufficient to enhance basal or stimulated FAK activation. This hypothesis is supported by the dose-dependent inhibition of GST-FAK autophosphorylation by recombinant $\beta$-arr2 in vitro. FAK and $\beta$-arrs are expressed at variable levels in adult tissues $[1,44]$ and the effects of $\beta$-arrs on FAK activity likely depend on their respective concentrations. Furthermore, FAK expression and autophosphorylation are increased in several human cancers [7] whereas changes in $\beta$-arrs are correlated with cancer progression and clinical outcome [44]. Changes of FAK and $\beta$-arr concentration in cancer cells might thus impact the regulation of FAK activation, particularly in response to GPCR activation.

In summary, we show that $\beta$-arrs are endogenous FAK inhibitors regulating FAK catalytic activity and FA formation under basal conditions. The release of basal $\beta$-arr-mediated inhibition of FAK is promoted by the recruitment of $\beta$-arr/FAK complexes to GPCRs. The subsequent interaction of $\beta$-arr with the AP-2 adaptor liberates FAK, allowing subsequent activation by adjacent active $G$ proteins. $\beta$-arrs therefore operate an on/off switch resulting in the localized control of FAK activity. Since FAK overexpression plays a critical role in tumour progression and metastasis formation, FAK regulation via $\beta$-arrs likely has an important impact on cancer development. 
Author contributions: RAA, IL, KS, MGHS, MB, SM and HE designed research. RAA, IL, KS, GA, ML, ABo, HK, ED and HE, performed research. Abe contributed new reagents. RAA, IL, KS, MGHS, HK, AA, MB SM and HE analysed data. HE supervised the project. RAA and HE wrote the manuscript, which was subsequently reviewed by all authors.

\section{Compliance with ethical standards}

Ethical standards the experiments comply with the current laws of France, the country in which they were performed.

Conflict of interest the authors declare that they have no competing interests. 


\section{References}

1. Corsi JM, Rouer E, Girault JA, Enslen H (2006) Organization and post-transcriptional processing of focal adhesion kinase gene. BMC Genomics 7:198. doi:10.1186/1471-2164-7-198

2. Nikolopoulos SN, Giancotti FG (2005) Netrin-integrin signaling in epithelial morphogenesis, axon guidance and vascular patterning. Cell Cycle 4 (3):e131-135

3. Rozengurt E (2007) Mitogenic signaling pathways induced by G protein-coupled receptors. J Cell Physiol 213

(3):589-602. doi:10.1002/jcp.21246

4. Schlaepfer DD, Hauck CR, Sieg DJ (1999) Signaling through focal adhesion kinase. Prog Biophys Mol Biol $71(3-4): 435-478$

5. Schlaepfer DD, Mitra SK, Ilic D (2004) Control of motile and invasive cell phenotypes by focal adhesion kinase. Biochim Biophys Acta 1692 (2-3):77-102

6. Schaller MD (2010) Cellular functions of FAK kinases: insight into molecular mechanisms and novel functions. J Cell Sci 123 (Pt 7):1007-1013. doi:10.1242/jcs.045112

7. Zhao J, Guan JL (2009) Signal transduction by focal adhesion kinase in cancer. Cancer Metastasis Rev 28 (12):35-49. doi:10.1007/s10555-008-9165-4

8. Corsi JM, Houbron C, Billuart P, Brunet I, Bouvree K, Eichmann A, Girault JA, Enslen H (2009) Autophosphorylation-independent and -dependent functions of focal adhesion kinase during development. J Biol Chem 284 (50):34769-34776. doi:10.1074/jbc.M109.067280

9. Furuta Y, Ilic D, Kanazawa S, Takeda N, Yamamoto T, Aizawa S (1995) Mesodermal defect in late phase of gastrulation by a targeted mutation of focal adhesion kinase, FAK. Oncogene 11 (10):1989-1995

10. Ilic D, Furuta Y, Kanazawa S, Takeda N, Sobue K, Nakatsuji N, Nomura S, Fujimoto J, Okada M, Yamamoto T (1995) Reduced cell motility and enhanced focal adhesion contact formation in cells from FAKdeficient mice. Nature 377 (6549):539-544. doi: 10.1038/377539a0

11. Ilic D, Kovacic B, McDonagh S, Jin F, Baumbusch C, Gardner DG, Damsky CH (2003) Focal adhesion kinase is required for blood vessel morphogenesis. Circ Res 92 (3):300-307

12. Roy-Luzarraga M, Hodivala-Dilke K (2016) Molecular Pathways: Endothelial Cell FAK-A Target for Cancer Treatment. Clin Cancer Res 22 (15):3718-3724. doi:10.1158/1078-0432.CCR-14-2021

13. Franchini KG (2012) Focal adhesion kinase -- the basis of local hypertrophic signaling domains. J Mol Cell Cardiol 52 (2):485-492. doi:10.1016/j.yjmcc.2011.06.021

14. Sulzmaier FJ, Jean C, Schlaepfer DD (2014) FAK in cancer: mechanistic findings and clinical applications. Nat Rev Cancer 14 (9):598-610. doi:10.1038/nrc3792

15. Peng X, Guan JL (2011) Focal adhesion kinase: from in vitro studies to functional analyses in vivo. Curr Protein Pept Sci 12 (1):52-67

16. Taylor KN, Schlaepfer DD (2018) Adaptive Resistance to Chemotherapy, A Multi-FAK-torial Linkage. Mol Cancer Ther 17 (4):719-723. doi:10.1158/1535-7163.MCT-17-1177

17. Tai YL, Chen LC, Shen TL (2015) Emerging roles of focal adhesion kinase in cancer. Biomed Res Int 2015:690690. doi:10.1155/2015/690690

18. Frame MC, Patel H, Serrels B, Lietha D, Eck MJ (2010) The FERM domain: organizing the structure and function of FAK. Nat Rev Mol Cell Biol 11 (11):802-814. doi: 10.1038/nrm2996 
19. Walkiewicz KW, Girault JA, Arold ST (2015) How to awaken your nanomachines: Site-specific activation of focal adhesion kinases through ligand interactions. Prog Biophys Mol Biol 119 (1):60-71. doi:10.1016/j.pbiomolbio.2015.06.001

20. Mousson A, Sick E, Carl P, Dujardin D, De Mey J, Ronde P (2018) Targeting Focal Adhesion Kinase Using Inhibitors of Protein-Protein Interactions. Cancers (Basel) 10 (9). doi:10.3390/cancers10090278

21. Zhao X, Peng X, Sun S, Park AY, Guan JL (2010) Role of kinase-independent and -dependent functions of FAK in endothelial cell survival and barrier function during embryonic development. J Cell Biol 189 (6):955965. doi:10.1083/jcb.200912094

22. Kleinschmidt EG, Schlaepfer DD (2017) Focal adhesion kinase signaling in unexpected places. Curr Opin Cell Biol 45:24-30. doi:10.1016/j.ceb.2017.01.003

23. Burridge K (2017) Focal adhesions: a personal perspective on a half century of progress. FEBS J 284 (20):3355-3361. doi:10.1111/febs. 14195

24. McLean GW, Carragher NO, Avizienyte E, Evans J, Brunton VG, Frame MC (2005) The role of focaladhesion kinase in cancer - a new therapeutic opportunity. Nat Rev Cancer 5 (7):505-515. doi:10.1038/nrc1647

25. Cohen LA, Guan JL (2005) Residues within the first subdomain of the FERM-like domain in focal adhesion kinase are important in its regulation. J Biol Chem 280 (9):8197-8207. doi:10.1074/jbc.M412021200

26. Cooper LA, Shen TL, Guan JL (2003) Regulation of focal adhesion kinase by its amino-terminal domain through an autoinhibitory interaction. Mol Cell Biol 23 (22):8030-8041

27. Lietha D, Cai X, Ceccarelli DF, Li Y, Schaller MD, Eck MJ (2007) Structural basis for the autoinhibition of focal adhesion kinase. Cell 129 (6):1177-1187. doi:10.1016/j.cell.2007.05.041

28. Toutant M, Costa A, Studler JM, Kadare G, Carnaud M, Girault JA (2002) Alternative splicing controls the mechanisms of FAK autophosphorylation. Mol Cell Biol 22 (22):7731-7743

29. Brami-Cherrier K, Gervasi N, Arsenieva D, Walkiewicz K, Boutterin MC, Ortega A, Leonard PG, Seantier B, Gasmi L, Bouceba T, Kadare G, Girault JA, Arold ST (2014) FAK dimerization controls its kinase-dependent functions at focal adhesions. EMBO J 33 (4):356-370. doi:10.1002/embj.201386399

30. Zachary I, Sinnett-Smith J, Rozengurt E (1992) Bombesin, vasopressin, and endothelin stimulation of tyrosine phosphorylation in Swiss $3 \mathrm{~T} 3$ cells. Identification of a novel tyrosine kinase as a major substrate. J Biol Chem 267 (27):19031-19034

31. Mehta PK, Griendling KK (2007) Angiotensin II cell signaling: physiological and pathological effects in the cardiovascular system. Am J Physiol Cell Physiol 292 (1):C82-97. doi:10.1152/ajpcell.00287.2006

32. Masia-Balague M, Izquierdo I, Garrido G, Cordomi A, Perez-Benito L, Miller NL, Schlaepfer DD, Gigoux V, Aragay AM (2015) Gastrin-stimulated Galpha13 Activation of Rgnef Protein (ArhGEF28) in DLD-1 Colon Carcinoma Cells. J Biol Chem 290 (24):15197-15209. doi:10.1074/jbc.M114.628164

33. Turner CE, Pietras KM, Taylor DS, Molloy CJ (1995) Angiotensin II stimulation of rapid paxillin tyrosine phosphorylation correlates with the formation of focal adhesions in rat aortic smooth muscle cells. J Cell Sci 108 (Pt 1):333-342

34. Yu HG, Nam JO, Miller NL, Tanjoni I, Walsh C, Shi L, Kim L, Chen XL, Tomar A, Lim ST, Schlaepfer DD (2011) p190RhoGEF (Rgnef) promotes colon carcinoma tumor progression via interaction with focal adhesion kinase. Cancer Res 71 (2):360-370. doi:10.1158/0008-5472.CAN-10-2894 
35. Feng X, Arang N, Rigiracciolo DC, Lee JS, Yeerna H, Wang Z, Lubrano S, Kishore A, Pachter JA, Konig GM, Maggiolini M, Kostenis E, Schlaepfer DD, Tamayo P, Chen Q, Ruppin E, Gutkind JS (2019) A Platform of Synthetic Lethal Gene Interaction Networks Reveals that the GNAQ Uveal Melanoma Oncogene Controls the Hippo Pathway through FAK. Cancer Cell 35 (3):457-472 e455. doi:10.1016/j.ccell.2019.01.009

36. Sood AK, Armaiz-Pena GN, Halder J, Nick AM, Stone RL, Hu W, Carroll AR, Spannuth WA, Deavers MT, Allen JK, Han LY, Kamat AA, Shahzad MM, McIntyre BW, Diaz-Montero CM, Jennings NB, Lin YG, Merritt WM, DeGeest K, Vivas-Mejia PE, Lopez-Berestein G, Schaller MD, Cole SW, Lutgendorf SK (2010) Adrenergic modulation of focal adhesion kinase protects human ovarian cancer cells from anoikis. J Clin Invest 120 (5):1515-1523. doi:10.1172/JCI40802

37. Lefkowitz RJ (2013) Arrestins come of age: a personal historical perspective. Prog Mol Biol Transl Sci 118:3-18. doi:10.1016/B978-0-12-394440-5.00001-2

38. Goodman OBJ, Krupnick JG, Santini F, Gurevich VV, Penn RB, Gagnon AW, Keen JH, Benovic JL (1996) $ß$-arrestin acts as a clathrin adaptor in endocytosis of the $\beta 2$-adrenergic receptor. Nature 383:447-450

39. Laporte SA, Oakley RH, Zhang J, Holt JA, Ferguson SS, Caron MG, Barak LS (1999) The beta2-adrenergic receptor/betaarrestin complex recruits the clathrin adaptor AP-2 during endocytosis. Proc Natl Acad Sci U S A $96(7): 3712-3717$.

40. Kook S, Gurevich VV, Gurevich EV (2014) Arrestins in apoptosis. Handb Exp Pharmacol 219:309-339. doi:10.1007/978-3-642-41199-1_16

41. Laporte SA, Scott MGH (2019) Beta-arrestins: Multitask Scaffolds Orchestrating the Where and When in Cell Signalling. In Walker J M (Ed) Beta-arrestins Methods in Molecular Biology, Springer, New-York 1957:955

42. McGovern KW, DeFea KA (2014) Molecular mechanisms underlying beta-arrestin-dependent chemotaxis and actin-cytoskeletal reorganization. Handb Exp Pharmacol 219:341-359. doi:10.1007/978-3-642-41199-1_17

43. Cleghorn WM, Branch KM, Kook S, Arnette C, Bulus N, Zent R, Kaverina I, Gurevich EV, Weaver AM, Gurevich VV (2015) Arrestins regulate cell spreading and motility via focal adhesion dynamics. Mol Biol Cell 26 (4):622-635. doi:10.1091/mbc.E14-02-0740

44. Enslen H, Lima-Fernandes E, Scott MG (2014) Arrestins as regulatory hubs in cancer signalling pathways. Handb Exp Pharmacol 219:405-425. doi:10.1007/978-3-642-41199-1_21

45. Lima-Fernandes E, Enslen H, Camand E, Kotelevets L, Boularan C, Achour L, Benmerah A, Gibson LC, Baillie GS, Pitcher JA, Chastre E, Etienne-Manneville S, Marullo S, Scott MG (2011) Distinct functional outputs of PTEN signalling are controlled by dynamic association with beta-arrestins. EMBO J 30 (13):25572568. doi:10.1038/emboj.2011.178

46. Tzenaki N, Aivaliotis M, Papakonstanti EA (2015) Focal adhesion kinase phosphorylates the phosphatase and tensin homolog deleted on chromosome 10 under the control of p110delta phosphoinositide-3 kinase. FASEB J. doi:10.1096/fj.15-274589

47. Storez H, Scott MG, Issafras H, Burtey A, Benmerah A, Muntaner O, Piolot T, Tramier M, Coppey-Moisan M, Bouvier M, Labbe-Jullie C, Marullo S (2005) Homo- and hetero-oligomerization of beta-arrestins in living cells. J Biol Chem 280 (48):40210-40215. doi:10.1074/jbc.M508001200 
48. Scott MG, Le Rouzic E, Perianin A, Pierotti V, Enslen H, Benichou S, Marullo S, Benmerah A (2002) Differential nucleocytoplasmic shuttling of beta-arrestins. Characterization of a leucine-rich nuclear export signal in beta-arrestin2. J Biol Chem 277 (40):37693-37701. doi:10.1074/jbc.M207552200

49. Burtey A, Schmid EM, Ford MG, Rappoport JZ, Scott MG, Marullo S, Simon SM, McMahon HT, Benmerah A (2007) The conserved isoleucine-valine-phenylalanine motif couples activation state and endocytic functions of beta-arrestins. Traffic 8 (7):914-931. doi:10.1111/j.1600-0854.2007.00578.x

50. Paradis JS, Ly S, Blondel-Tepaz E, Galan JA, Beautrait A, Scott MG, Enslen H, Marullo S, Roux PP, Bouvier M (2015) Receptor sequestration in response to beta-arrestin-2 phosphorylation by ERK1/2 governs steady-state levels of GPCR cell-surface expression. Proc Natl Acad Sci U S A 112 (37):E5160-5168. doi:10.1073/pnas.1508836112

51. Scott MG, Pierotti V, Storez H, Lindberg E, Thuret A, Muntaner O, Labbe-Jullie C, Pitcher JA, Marullo S (2006) Cooperative regulation of extracellular signal-regulated kinase activation and cell shape change by filamin A and beta-arrestins. Mol Cell Biol 26 (9):3432-3445. doi:10.1128/MCB.26.9.3432-3445.2006

52. Hamdan FF, Rochdi MD, Breton B, Fessart D, Michaud DE, Charest PG, Laporte SA, Bouvier M (2007) Unraveling $\mathrm{G}$ protein-coupled receptor endocytosis pathways using real-time monitoring of agonist-promoted interaction between beta-arrestins and AP-2. J Biol Chem 282 (40):29089-29100. doi:10.1074/jbc.M700577200

53. Ramsay D, Kellett E, McVey M, Rees S, Milligan G (2002) Homo- and hetero-oligomeric interactions between G-protein-coupled receptors in living cells monitored by two variants of bioluminescence resonance energy transfer (BRET): hetero-oligomers between receptor subtypes form more efficiently than between less closely related sequences. Biochem J 365 (Pt 2):429-440. doi:10.1042/BJ20020251

54. Namkung Y, Radresa O, Armando S, Devost D, Beautrait A, Le Gouill C, Laporte SA (2015) Quantifying biased signaling in GPCRs using BRET-based biosensors. Methods. doi:10.1016/j.ymeth.2015.04.010

55. Oishi A, Dam J, Jockers R (2019) beta-arrestin-2 BRET biosensors detect different beta-arrestin-2 conformations in interaction with GPCRs. ACS Sens. doi:10.1021/acssensors.9b01414

56. Namkung Y, Le Gouill C, Lukashova V, Kobayashi H, Hogue M, Khoury E, Song M, Bouvier M, Laporte SA (2016) Monitoring G protein-coupled receptor and beta-arrestin trafficking in live cells using enhanced bystander BRET. Nat Commun 7:12178. doi:10.1038/ncomms12178

57. Wei H, Ahn S, Shenoy SK, Karnik SS, Hunyady L, Luttrell LM, Lefkowitz RJ (2003) Independent betaarrestin 2 and G protein-mediated pathways for angiotensin II activation of extracellular signal-regulated kinases 1 and 2. Proc Natl Acad Sci U S A 100 (19):10782-10787. doi:10.1073/pnas.1834556100

58. Auger-Messier M, Arguin G, Chaloux B, Leduc R, Escher E, Guillemette G (2004) Down-regulation of inositol 1,4,5-trisphosphate receptor in cells stably expressing the constitutively active angiotensin II N111GAT(1) receptor. Mol Endocrinol 18 (12):2967-2980. doi:10.1210/me.2003-0488

59. Charest PG, Bouvier M (2003) Palmitoylation of the V2 vasopressin receptor carboxyl tail enhances betaarrestin recruitment leading to efficient receptor endocytosis and ERK1/2 activation. J Biol Chem 278 (42):41541-41551. doi:10.1074/jbc.M306589200

60. Gesty-Palmer D, Chen M, Reiter E, Ahn S, Nelson CD, Wang S, Eckhardt AE, Cowan CL, Spurney RF, Luttrell LM, Lefkowitz RJ (2006) Distinct beta-arrestin- and G protein-dependent pathways for parathyroid hormone receptor-stimulated ERK1/2 activation. J Biol Chem 281 (16):10856-10864. doi:10.1074/jbc.M513380200 
61. Olivo-Marin J-C (2002) Extraction of Spots iun Biological Images using Multi-scale products. Pattern Recognition 35 (9):1989-1996. doi:10.1016/S0031-3203(01)00127-3

62. Alexander RA, Lot I, Enslen H (2019) Methods to characterize protein interaction with beta-arrestin in Cellulo. In Walker J M (Ed) Beta-arrestins Methods in Molecular Biology, Springer, New-York 1957:139-158

63. Kohout TA, Lin FS, Perry SJ, Conner DA, Lefkowitz RJ (2001) beta-Arrestin 1 and 2 differentially regulate heptahelical receptor signaling and trafficking. Proc Natl Acad Sci U S A 98 (4):1601-1606. doi:10.1073/pnas.041608198

64. Min J, Defea K (2011) beta-arrestin-dependent actin reorganization: bringing the right players together at the leading edge. Mol Pharmacol 80 (5):760-768. doi:10.1124/mol.111.072470

65. Alekhina O, Marchese A (2016) beta-Arrestin1 and Signal-transducing Adaptor Molecule 1 (STAM1) Cooperate to Promote Focal Adhesion Kinase Autophosphorylation and Chemotaxis via the Chemokine Receptor CXCR4. J Biol Chem 291 (50):26083-26097. doi:10.1074/jbc.M116.757138

66. Anthony DF, Sin YY, Vadrevu S, Advant N, Day JP, Byrne AM, Lynch MJ, Milligan G, Houslay MD, Baillie GS (2011) beta-Arrestin 1 inhibits the GTPase-activating protein function of ARHGAP21, promoting activation of RhoA following angiotensin II type 1A receptor stimulation. Mol Cell Biol 31 (5):1066-1075. doi:10.1128/MCB.00883-10

67. Barnes WG, Reiter E, Violin JD, Ren XR, Milligan G, Lefkowitz RJ (2005) beta-Arrestin 1 and Galphaq/11 coordinately activate RhoA and stress fiber formation following receptor stimulation. J Biol Chem 280 (9):80418050. doi:10.1074/jbc.M412924200

68. Godin CM, Ferguson SS (2010) The angiotensin II type 1 receptor induces membrane blebbing by coupling to Rho A, Rho kinase, and myosin light chain kinase. Mol Pharmacol 77 (6):903-911. doi:10.1124/mol.110.063859

69. Toutant M, Studler JM, Burgaya F, Costa A, Ezan P, Gelman M, Girault JA (2000) Autophosphorylation of Tyr397 and its phosphorylation by Src-family kinases are altered in focal-adhesion-kinase neuronal isoforms. Biochem J 348 Pt 1:119-128

70. Luttrell LM (2014) Minireview: More than just a hammer: ligand "bias" and pharmaceutical discovery. Mol Endocrinol 28 (3):281-294. doi:10.1210/me.2013-1314

71. Gaborik Z, Jagadeesh G, Zhang M, Spat A, Catt KJ, Hunyady L (2003) The role of a conserved region of the second intracellular loop in AT1 angiotensin receptor activation and signaling. Endocrinology 144 (6):22202228. doi:10.1210/en.2002-0135

72. Zimmerman B, Beautrait A, Aguila B, Charles R, Escher E, Claing A, Bouvier M, Laporte SA (2012) Differential beta-arrestin-dependent conformational signaling and cellular responses revealed by angiotensin analogs. Sci Signal 5 (221):ra33. doi:10.1126/scisignal.2002522

73. Krupnick JG, Goodman OB, Jr., Keen JH, Benovic JL (1997) Arrestin/clathrin interaction. Localization of the clathrin binding domain of nonvisual arrestins to the carboxy terminus. J Biol Chem 272 (23):15011-15016

74. Laporte SA, Oakley RH, Holt JA, Barak LS, Caron MG (2000) The interaction of beta-arrestin with the AP2 adaptor is required for the clustering of beta 2-adrenergic receptor into clathrin-coated pits. J Biol Chem 275 (30):23120-23126. doi:10.1074/jbc.M002581200 
75. Scott MG, Benmerah A, Muntaner O, Marullo S (2002) Recruitment of activated G protein-coupled receptors to pre-existing clathrin-coated pits in living cells. J Biol Chem 277 (5):3552-3559. doi:10.1074/jbc.M106586200

76. Beautrait A, Paradis JS, Zimmerman B, Giubilaro J, Nikolajev L, Armando S, Kobayashi H, Yamani L, Namkung Y, Heydenreich FM, Khoury E, Audet M, Roux PP, Veprintsev DB, Laporte SA, Bouvier M (2017) A new inhibitor of the beta-arrestin/AP2 endocytic complex reveals interplay between GPCR internalization and signalling. Nat Commun 8:15054. doi:10.1038/ncomms15054

77. Lopez-Colome AM, Lee-Rivera I, Benavides-Hidalgo R, Lopez E (2017) Paxillin: a crossroad in pathological cell migration. J Hematol Oncol 10 (1):50. doi:10.1186/s13045-017-0418-y

78. Naser R, Aldehaiman A, Diaz-Galicia E, Arold ST (2018) Endogenous Control Mechanisms of FAK and PYK2 and Their Relevance to Cancer Development. Cancers (Basel) 10 (6). doi:10.3390/cancers10060196

79. Abbi S, Ueda H, Zheng C, Cooper LA, Zhao J, Christopher R, Guan JL (2002) Regulation of focal adhesion kinase by a novel protein inhibitor FIP200. Mol Biol Cell 13 (9):3178-3191. doi:10.1091/mbc.e02-05-0295

80. Lima-Fernandes E, Misticone S, Boularan C, Paradis JS, Enslen H, Roux PP, Bouvier M, Baillie GS, Marullo S, Scott MG (2014) A biosensor to monitor dynamic regulation and function of tumour suppressor PTEN in living cells. Nat Commun 5:4431. doi:10.1038/ncomms5431

81. Brunton VG, Avizienyte E, Fincham VJ, Serrels B, Metcalf CA, 3rd, Sawyer TK, Frame MC (2005) Identification of Src-specific phosphorylation site on focal adhesion kinase: dissection of the role of $\mathrm{Src} \mathrm{SH} 2$ and catalytic functions and their consequences for tumor cell behavior. Cancer Res 65 (4):1335-1342. doi:10.1158/0008-5472.CAN-04-1949

82. Abu-Ghazaleh R, Kabir J, Jia H, Lobo M, Zachary I (2001) Src mediates stimulation by vascular endothelial growth factor of the phosphorylation of focal adhesion kinase at tyrosine 861, and migration and anti-apoptosis in endothelial cells. Biochem J 360 (Pt 1):255-264. doi:10.1042/0264-6021:3600255

83. Brunton VG, Frame MC (2008) Src and focal adhesion kinase as therapeutic targets in cancer. Curr Opin Pharmacol 8 (4):427-432. doi:10.1016/j.coph.2008.06.012

84. Kostourou V, Lechertier T, Reynolds LE, Lees DM, Baker M, Jones DT, Tavora B, Ramjaun AR, Birdsey GM, Robinson SD, Parsons M, Randi AM, Hart IR, Hodivala-Dilke K (2013) FAK-heterozygous mice display enhanced tumour angiogenesis. Nat Commun 4:2020. doi:10.1038/ncomms3020

85. Lim Y, Han I, Jeon J, Park H, Bahk YY, Oh ES (2004) Phosphorylation of focal adhesion kinase at tyrosine 861 is crucial for Ras transformation of fibroblasts. J Biol Chem 279 (28):29060-29065. doi:10.1074/jbc.M401183200

86. Lunn JA, Jacamo R, Rozengurt E (2007) Preferential phosphorylation of focal adhesion kinase tyrosine 861 is critical for mediating an anti-apoptotic response to hyperosmotic stress. J Biol Chem 282 (14):10370-10379. doi:10.1074/jbc.M607780200

87. Ma X, Zhao Y, Daaka Y, Nie Z (2012) Acute activation of beta2-adrenergic receptor regulates focal adhesions through betaArrestin2- and p115RhoGEF protein-mediated activation of RhoA. J Biol Chem 287 (23):18925-18936. doi:10.1074/jbc.M112.352260 


\section{Figure legends}

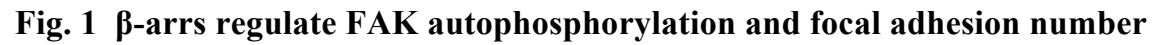

a Adherent wt and $\beta$-arr1 $1^{-/} / \beta$-arr2 ${ }^{-/}$(DKO) MEF cells were serum starved, lysed and analysed for FAK-pY397, FAK and $\beta$-arrs by immunoblotting. The mean \pm s.e.m. of pY397/FAK values, calculated from three independent experiments, was normalized to the value obtained in wt MEFs. ( ${ }^{* *} P$ value $<0.01, t$-test). b Immunoblotting for FAK-pY397 and total FAK was performed after IP FAK from lysates of serum-deprived MEF cells held in suspension for $60 \mathrm{~min}$ at $37^{\circ} \mathrm{C}$. Quantification (lower panel, ${ }^{*} P<0.1$, $t$-test) was performed as in (a). c Confocal images of serum-starved MEF cells fixed and stained for paxillin (green) and pY397-FAK (grey). Merge is shown as paxillin (green) and pY397-FAK (magenta). Scale bar=5 $\mu \mathrm{m}$. d-f FA number per cell indicated by paxillin (d) or pY397-FAK staining (e) and pY397-FAK intensity staining in focal adhesions (FA) per cell (f) were quantified in MEFs from (c). For each condition, 35-40 cells from different coverslips were quantified. $(* * * P<0.001, t$-test).

\section{Fig. 2 FAK interacts with $\beta$-arrs}

a IPs with HA antibodies were performed on lysates of HEK-293 cells transfected with HA-FAK and GFP or GFP- $\beta$-arr1 or GFP- $\beta$-arr2. Lysates and IP were immunoblotted for GFP- $\beta$-arrs and HA-FAK. b IPs with antimyc antibodies were performed on lysates of HEK-293 transfected with HA-FAK, Myc- $\beta$-arr1 or Myc- $\beta$-arr2. Lysates and IP were immunoblotted for $\beta$-arrs and HA-FAK. c Yeast reporter strain HF7c was transformed with the indicated plasmids. Growth in the absence of histidine indicates interaction between $\beta$-arr 2 and FAK fusion proteins. d Purified GST, GST- $\beta$-arr1 or GST- $\beta$-arr2 bound to glutathione-agarose beads (Coomassie staining) were incubated with HEK-293 lysates transfected with HA-FAK and immunoblotted with an anti-HA antibody. Input is $5 \%$ of cell lysate. e Purified GST, GST- $\beta$-arr1 or GST- $\beta$-arr2 bound to glutathione-agarose beads (Ponceau red staining) were incubated with HEK-293 lysates and immunoblotted for endogenous FAK. Input is $5 \%$ of cell lysate. f IP with rabbit anti- $\beta$-arr1/2 antibodies or rabbit IgG were performed on rat brain lysates. Lysates and IP were immunoblotted for FAK and $\beta$-arrs. g-h BRET saturation experiments were performed on adherent HEK-293 cells (g) or HEK-293 in suspension (h) after co-transfection with a constant amount of plasmid for RlucII-FAK and increasing concentrations of $\beta$-arr1-GFP ${ }_{10}$ or $\beta$-arr2-GFP 10 plasmids. mBRET values $(\beta$-arr1-GFP 10 : red circles, $\beta$-arr2-GFP 10 : black squares) are means \pm s.e.m. of three independent experiments (three replicates for each condition per experiment). BRET $_{50}$ values were $6.89 \pm 1.38$ and $6.0 \pm 1.09$ for $\beta$-arr1-GFP 10 and $\beta$-arr2-GFP 10 , respectively (g).

\section{Fig. $3 \beta$-arrs regulate FAK catalytic activity and focal adhesion number}

a GST-FAK was incubated with PBS (Ctrl) or equivalent amounts of purified HA- $\beta$-arr2 or HA-FLNA(23-24) for $10 \mathrm{~min}$ on ice. Aliquots were taken at the initiation (0) of the autophosphorylation assay and after $10 \mathrm{~min}$ incubation at $30^{\circ} \mathrm{C}$ and immunoblotted for pY397, FAK and HA. Data represent mean \pm s.e.m. of pY397FAK/FAK normalized to the control (0) time point set to 1 , from five independent experiments. b $\mathrm{HEK}_{-} \mathrm{AT}_{1 \mathrm{~A}} \mathrm{R}$ cells were transfected with control, $\beta$-arr1, $\beta$-arr2 or $\beta$-arr1/2 siRNA, serum starved and left untreated or stimulated with 100nM AngII for 2 min. Lysates were immunoblotted with the indicated antibodies. Data on the right panel represent means \pm s.e.m. of pY397-FAK/FAK values from five independent experiments normalized to unstimulated cells transfected with control siRNA and set to $1 .{ }^{*} P<0.05 ; * * P<0.01 ; * * * P<0.001$; one-way 
Anova, Bonferroni. Values obtained for $\beta$-arr siRNA-treated cells (targeting either isoform or both) were not significantly different either in basal or stimulated conditions. c HEK-AT ${ }_{1 \mathrm{~A}} \mathrm{R}$ cells prepared as in (b) and seeded on collagen-coated coverslips, were untreated or stimulated with 100nM AngII for 5 min and immunostained for pY397-FAK (green) and Vinculin (grey) with the merge shown as pY397-FAK/green and Vinculin/magenta. Scale bar $=5 \mu \mathrm{m}$. $(\mathbf{d}-\mathbf{e})$. For each condition, the number of FA per cell and the pY397-FAK intensity staining in FA per cell were quantified for 20-30 cells from different coverslips. (a-e) $* P<0.05 ; * * P<0.01 ; * * * P<0.001$; one-way Anova, Bonferroni.

\section{Fig. 4 FAK N-terminal domain is necessary for $\beta$-arr interaction and FAK inhibition}

a Schematic of FAK truncations used in (b-e). FAK-Nter (1-402), FAK- $\Delta$ Nter (403-1055). b HF7c yeast reporter strain was transformed with the indicated plasmids. In the absence of histidine, $\beta$-arr2 elicited growth with FAK-Nter but not with FAK- $\Delta$ Nter. c IPs were performed with anti-HA antibodies on lysates of HEK-293 cells transfected with the indicated plasmids. Lysates and IP were immunoblotted with anti-myc and anti-HA antibodies. d HEK-293 cells were co-transfected with plasmids coding for $\beta$-arr2-GFP 10 , FAK-RlucII and FAKNter at a 3:1 FAK-Nter/FAK-RlucII or empty vector/FAK-RlucII ratio. Graph represents mean \pm s.e.m of BRET values from three independent experiments (three replicates per experiment), normalized to the BRET observed in cells transfected without FAK-Nter, and set to $100 \%(* * P<0.01, t$-test $)$. Samples were lysed and immunoblotted using anti-FAK and anti-GFP antibodies (right panel). e HEK-293 cells were treated with indicated siRNA for $24 \mathrm{hr}$ followed by transfection with HA-FAK or HA-FAK(376-1055) plasmids for another $24 \mathrm{hr}$ and serum starved. IP performed with anti-HA antibodies on the lysates were immunoblotted for pY397FAK and FAK, and lysate for $\beta$-arrs. Data represent the fold increase of pY397-FAK/FAK or pY397-FAK(3761055)/FAK(376-1055) in the $\beta$-arr knockdown condition normalized to their respective control siRNA condition. Mean \pm s.e.m. of three independent experiments are shown $(* * * P<0.001, t$-test).

Fig. 5 FAK autophosphorylation in response to AngII stimulation is mediated by G protein-dependent pathways

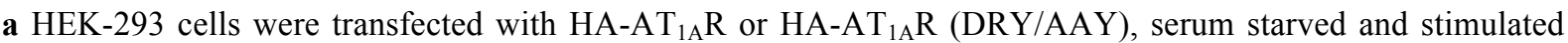
with 100nM AngII for the indicated times. Lysates were immunoblotted for pY397-FAK, FAK, HA and vinculin. Data shown (bottom panel) represent mean \pm s.e.m of pY397-FAK/FAK values $\left(H A-A T_{1 A} R\right.$ : black circles, HA$\mathrm{AT}_{1 \mathrm{~A}} \mathrm{R}$ (DRY/AAY): red squares) normalized to untreated cells transfected with the HA-AT ${ }_{1 \mathrm{~A}} \mathrm{R}$ and set to 1 from three independent experiments. b Real-time BRET measurement of HEK-293 cells co-transfected with $\mathrm{GFP}_{10}-\beta$-arr2-RlucII and HA-AT ${ }_{1 \mathrm{~A}} \mathrm{R}$ (black symbols) or HA-AT ${ }_{1 \mathrm{~A}} \mathrm{R}$ (DRY/AAY) (red symbols), left untreated (AngII, black circles and red base down-triangles) or stimulated with 100nM AngII (+AngII, black squares and red base up-triangles). Graph represents agonist-induced $\triangle$ mBRET mean values (mBRET value - mBRET value at time 0) from three independent experiments (3-8 replicates for each condition per experiment). c Following serum deprivation, HEK-AT ${ }_{1 \mathrm{~A}} \mathrm{R}$ cells were stimulated with $100 \mathrm{nM}$ AngII or with $10 \mu \mathrm{M}$ of the $\beta$-arr-biased ligand DVG for the indicated time. Lysed samples were immunoblotted for pY397-FAK, and FAK. Quantification (AngII: black circles, DVG: red squares) was performed from three independent experiments as in a. d Real-time BRET measurement of HEK-293 cells co-transfected with GFP $10-\beta$-arr2-RlucII and HA$\mathrm{AT}_{1 \mathrm{~A}} \mathrm{R}$, left untreated (-AngII, black circles) or stimulated with $100 \mathrm{nM}$ AngII (+AngII, red squares) or $10 \mu \mathrm{M}$ 
DVG (+DVG, green triangles). Graph represents $\triangle$ mBRET mean values from three independent experiments (46 replicates for each condition per experiment).

Fig. 6 Interaction of $\beta$-arr2 with AP-2 upon AngII stimulation releases FAK from $\beta$-arr2 and its constitutive inhibition over FAK

a HEK cells were transfected with HA-FAK and GFP or $\beta$-arr-GFP, serum starved and left unstimulated or treated with 100nM AngII (10 min). IPs were performed using anti-GFP antibodies and both IPs and lysates were immunoblotted for HA-FAK, pY397-FAK and GFP. Data represents mean \pm s.e.m. of the ratio of coimmunoprecipitated HA-FAK to immunoprecipitated GFP normalised to GFP in the lysate, and normalised to untreated cells set to $100 \%$ from three independent experiments $(* * P<0.01, t$-test). b HEK-293 cells cotransfected with HA-AT ${ }_{1 \mathrm{~A}} \mathrm{R}$, RlucII-FAK and $\beta$-arr2-GFP ${ }_{10}$ or $\beta$-arr2 $\triangle \mathrm{AP}-2-\mathrm{GFP}_{10}$ were untreated or stimulated with $1 \mu \mathrm{M}$ AngII for 15 min and BRET measured. Graph represents mean \pm s.e.m. of BRET normalized to BRET in untreated cells transfected with $\beta$-arr2-GFP ${ }_{10}$ and set to $100 \%$ from three independent experiments (4-6 replicates for each condition per experiment). ${ }^{*} P<0.05$; one-way Anova, Bonferroni. c Live cell imaging of GFP-FAK and mCherry- $\beta$-arr2 $\triangle$ AP-2 upon AngII treatment. Confocal images of HEK-293 cells transfected with $\mathrm{HA}-\mathrm{AT}_{1 \mathrm{~A}} \mathrm{R}$, GFP-FAK (grey) and mCherry- $\beta$-arr2 $\triangle \mathrm{AP}-2$ (grey) were acquired in absence of stimulation (basal) and $5 \mathrm{~min}$ after the addition of $100 \mathrm{nM}$ AngII. Merged images are shown as GFP-FAK in green and mCherry- $\beta$-arr $2 \triangle \mathrm{AP}-2$ in red. d HEK- $\mathrm{AT}_{1 \mathrm{~A}} \mathrm{R}$ cells were transfected with indicated plasmids, processed as in (a) and both IPs and lysates were immunoblotted for HA-FAK and GFP- $\beta$-arrs. Three independent experiments were quantified as in (a). ${ }^{*} P<0.05$, one way Anova. e HEK-AT ${ }_{1 \mathrm{~A}} \mathrm{R}$ cells transfected with $\beta$-arr2-GFP or $\beta$ arr2 $\triangle \mathrm{AP}-2-\mathrm{GFP}$, were serum starved and unstimulated or stimulated with 100nM AngII for the indicated time. Lysates were immunoblotted as indicated. Data represent mean \pm s.e.m of pY397-FAK/FAK and phosphoPaxillin/Paxillin values ( $\beta$-arr2-GFP: black circles, $\beta$-arr2 $\triangle$ AP-2-GFP: red squares), normalized to untreated $\beta$ arr2-GFP-transfected cells and set to one from three independent experiments.

Figure. 7. Inhibition of $\beta$-arr2-AP-2 interaction downregulates FAK activation in response to AngII stimulation

a HEK-293 cells co-transfected with $\mathrm{HA}-\mathrm{AT}_{1 \mathrm{~A}} \mathrm{R}$, RlucII-FAK and $\beta$-arr2-GFP ${ }_{10}$ plasmids were pre-treated with DMSO or $50 \mu \mathrm{M}$ Barbadin for $10 \mathrm{~min}$ and untreated or stimulated with $1 \mu \mathrm{M}$ AngII (15 min) before BRET measurements. Graph represents mean \pm s.e.m. of BRET values normalized to the value obtained in control cells (DMSO) left untreated and set to 100\% from three independent experiments (3-6 replicates for each condition per experiment). ${ }^{* * P}<0.01$; one-way Anova, Bonferroni. b-c $\mathrm{HEK}-\mathrm{AT}_{1 \mathrm{~A}} \mathrm{R}$ (b) or HEK-V2R (c) cells were serum starved overnight, pre-treated with DMSO or $50 \mu \mathrm{M}$ Barbadin for $10 \mathrm{~min}$ and stimulated with $100 \mathrm{nM}$ AngII (b) or $100 \mathrm{nM}$ AVP (c) for the indicated time. Lysates were immunoblotted for pY397-FAK, FAK, phospho-Paxillin and Paxillin. Data calculated from three independent experiments, represent mean \pm s.e.m of pY397-FAK/FAK and phospho-Paxillin/Paxillin values (DMSO: black circles, Barbadin: red squares) normalized to untreated cells and set to one. 
Figure. 8. Schematic model for the regulation of FAK activity by $\beta$-arrs under basal and GPCRstimulated conditions

Under basal conditions, both $\beta$-arr1 and $\beta$-arr2 form molecular complexes with a pool of nonautophosphorylated FAK in the cytoplasm, inhibiting its catalytic activity and negatively regulating both the amount of pY397-FAK in FA and FA number. Agonist (A)-mediated GPCR activation triggers G-protein activation (illustrated by GDP to GTP exchange); the receptors are then phosphorylated (P) by GRKs (not shown) and recruit $\beta$-arr-FAK complexes. $\beta$-arr interaction with AP-2 results in the release of FAK from its complex with $\beta$-arr, which relieves the inhibition exerted by $\beta$-arr on FAK, followed by FAK activation by the G protein. 


\section{Beta-arrestins operate an on/off control switch for Focal Adhesion Kinase activity}

Revu Ann Alexander ${ }^{1}$, Isaure Lot $^{1}$, Kusumika Saha ${ }^{1}$, Guillaume Abadie ${ }^{1}$, Mireille Lambert ${ }^{1}$, Eleonore Decosta ${ }^{1}$, Hiroyuki Kobayashi ${ }^{2}$, Alexandre Beautrait ${ }^{2}$, Aurélie Borrull ${ }^{1}$, Atef Asnacios ${ }^{3}$, Michel Bouvier ${ }^{2}$, Mark G. H.

Scott $^{1}$, Stefano Marullo ${ }^{1}$ and Hervé Enslen ${ }^{1 *}$

${ }^{1}$ : Institut Cochin, Inserm U 1016, CNRS UMR8104, Université de Paris, Paris, France.

${ }^{2}$ : Department of Biochemistry and the Institute for Research in Immunology and Cancer, Université de Montréal, Montréal, Québec H3C 3J7, Canada.

${ }^{3}$ : Laboratoire Matière et Systèmes Complexes, UMR 7057, Université de Paris, Paris, France.

(*) Corresponding author: herve.enslen@inserm.fr

Address: Institut Cochin, Inserm U 1016, CNRS UMR8104, Université de Paris

27 rue du Faubourg Saint-Jacques, 75014 Paris, France.

Tel: +33140516554

Fax: +3314051 6535

\section{Supplementary material}




\section{Supplemental Methods}

Inverse BRET Assays. HEK-293 cells were transfected with constant amounts of $\beta$-arr1/2-GFP 10 BRET acceptor plasmid together with increasing concentrations of the RlucII-FAK BRET donor plasmid. In the case of a specific interaction, the efficiency of energy transfer depends on the concentration of the BRET donor resulting in a hyperbolic curve, whereas in a model of random (non specific) collision, BRET is independent of donor concentration: its level does not change and a straight horizontal line would be expected.

$24 \mathrm{hr}$ post-transfection, cells were prepared as described in the Materials and Methods section. The fluorescence and luminescence measurements were next performed using a Mithras LB 940 (Berthold Technologies). The amount of acceptor protein was determined by measuring the fluorescence using an excitation filter at $405 \mathrm{~nm}$. This was followed by addition of the Luciferase substrate-Coelenterazine 400a (Interchim) at a final concentration of $2.5 \mu \mathrm{M}$ and measurements of RlucII and $\mathrm{GFP}_{10}$ luminescence at $410 \mathrm{~nm}$ and $515 \mathrm{~nm}$ respectively. The ratio of light emitted by $\mathrm{GFP}_{10}$ over light emitted by RlucII was determined as the BRET ratio. For all BRET experiments, BRET ratios were multiplied by 1000 and expressed as mBRET units. The inverse assay curves were obtained by plotting the BRET ratios as a function of the donor luminescence.

\section{Supplementary data}

\section{Legends of Supplementary Figures}

Supplementary Figure 1: Increased pY397-FAK in DKO is a direct consequence of the absence of $\beta$-arrs, pY576/577-FAK and pY925-FAK are upregulated in DKO MEFs.

a. Adherent wt and $\beta$-arr $1^{-/} / \beta$-arr2 ${ }^{-/}$(DKO) MEF cells were transfected with empty (-), Flag-tagged $\beta$-arr1 or $\beta$ arr2 plasmids, serum starved, lysed and analysed for FAK-pY397, FAK and $\beta$-arrs by immunoblotting. The mean \pm s.e.m. of pY397/FAK values calculated from three independent experiments, were normalized to the value obtained in wt MEFs. ${ }^{* *} P<0.001$, one-way Anova, Bonferroni . b Adherent wt and $\beta$-arr ${ }^{-/ /} / \beta$-arr2 ${ }^{-/-}$ (DKO) MEF cells were serum starved, lysed and analysed for FAK-pY576/577, FAK-pY861, FAK-pY925, FAK, $\beta$-arrs and GAPDH by immunoblotting. The mean \pm s.e.m. of pFAK/FAK values, calculated from 6 independent experiments for pY576/577 and FAK-pY925 and from 4 experiments for pY861, was normalized to the value obtained in wt MEFs and set to one. ( ${ }^{* * * *} P$ value $<0.0001, t$-test).

Supplementary Figure 2: Interaction of $\beta$-arrs with FAK.

a Control BRET saturation experiments between RlucII-FAK (constant amount) and GFP10 (increasing amounts) produced a linear curve indicating random collision. $\mathbf{b}$ The BRET specificity between FAK and $\beta$-arrs was further confirmed by an inverse BRET experiment. HEK-293 cells were co-transfected with a constant amount of $\beta$-arr1-GFP10 (red circles) or $\beta$-arr2-GFP10 (black squares) plasmids and increasing amounts of RlucII-FAK plasmid as described in the Supplemental Methods. The dotted line symbolizes the result that would be observed for random collision (non specific interaction/proximity), in which no change in the BRET level is observed. Values are means \pm s.e.m. from three independent experiments (three replicates per condition in each experiment). 
Supplementary Figure 3: Dose-dependent inhibition of GST-FAK catalytic activity by His-HA- $\beta$-arr2, efficacy of $\beta$-arrs siRNA.

a GST-FAK was incubated with either PBS (ctrl) or increasing amounts of purified recombinant His $_{6}$-HA- $\beta$-arr2 ( $\beta$-arr2) on ice for $10 \mathrm{~min}$. The molar ratio for each $\beta$-arr2/FAK ratio is indicated. Autophosphorylation assays were initiated by the addition of $100 \mu \mathrm{M}$ ATP and performed at $30^{\circ} \mathrm{C}$ for $10 \mathrm{~min}(10)$. For each condition, an aliquot of the mix was taken at the time of ATP addition (0). Quantification of samples immunoblotted for pY397 and FAK is shown. The data represent the mean \pm s.e.m. of pY397-FAK/FAK values normalized to the control (ctrl) at the time of ATP addition (0) and set to one from independent experiments (n=6). (* $P$ value $<$ $0.05, * * * P$ value $<0.001$; one-way Anova). b-c The efficacy of $\beta$-arr1 (b) and $\beta$-arr2 (c) silencing in Fig. $3 b$ was determined by normalizing residual $\beta$-arr1 and $\beta$-arr2 to vinculin for each specific siRNA. The normalized remaining $\beta$-arr1 and $\beta$-arr2 (\%) were compared to values in HEK-AT ${ }_{1 \mathrm{~A}} \mathrm{R}$ cells transfected with control siRNA. Bar graphs and error bars represent mean \pm s.e.m. values from five independent experiments.

Supplementary Figure 4: FAK kinase activation and focal adhesion formation in response to AngII.

a HEK-AT ${ }_{1 \mathrm{~A}} \mathrm{R}$ cells were serum starved and stimulated with 100nM AngII for the indicated time before lysis. Samples were immunoblotted for FAK phosphorylated on Tyr-397, Tyr-576 and 577 (pY576-577), FAK and vinculin. One representative western blot from three independent experiments is shown. $\mathbf{b} H E K-\mathrm{AT}_{1 \mathrm{~A}} \mathrm{R}$ cells were seeded on collagen-coated coverslips, serum starved and stimulated with 100nM AngII for the indicated times, as in (a). After fixation cells were immunostained for FAK (red), Vinculin (green) and actin (grey, phalloidin). Scale bar $=10 \mu \mathrm{m}$.

Supplementary Figure 5: Mutation of Y397 in FAK does not prevent basal FAK- $\beta$-arr2 interaction in unstimulated cells.

a RlucII-FAK (black squares) and RlucII-Y397F-FAK (red circles) were compared for their interaction with $\beta$ arr2-GFP10 using BRET saturation experiments. HEK-293 cells were co-transfected with a constant amount of RlucII-FAK or RlucII-Y397F-FAK (the BRET donor) plasmids and increasing concentrations of $\beta$-arr2-GFP10 (the BRET acceptor) plasmids. b Lysates of HEK-293 cells used in panel (a) corresponding to minimal saturating concentration of the BRET acceptor were immunoblotted for pY397-FAK, FAK and GFP.

Supplementary Figure 6: Stimulation of $\mathrm{AT}_{1 \mathrm{~A}} \mathrm{R}$ or $\mathrm{V} 2 \mathrm{R}$ promotes $\beta$-arr2/AP-2 interaction. HEK-293 cells co-transfected with YFP-AP2, $\beta$ arr2-Luc and HA-AT ${ }_{1 \mathrm{~A}}$ R or SNAP-V2R-Flag were left untreated or stimulated with $1 \mu \mathrm{M}$ AngII or $1 \mu \mathrm{M}$ AVP for the indicated times and BRET was measured. Graph represents means \pm s.e.m. from three independent experiments. (**** $P$ value $<0.0001$; two-way Anova, Bonferroni).

Supplementary Figure 7: Mutation of the AP-2 binding site in $\beta$-arr2 does not prevent basal FAK/ $\beta$-arr2 interaction in unstimulated cells and AngII-stimulated $\beta$-arr2 recruitment to the receptor. a BRET saturation curves for HEK-293 cells co-transfected with a constant amount of RlucII-FAK plasmid and increasing concentrations of $\beta$-arr2-GFP10 (black circles) or $\beta$-arr2 $\triangle$ AP2-GFP10 (red squares) plasmids. b HEK-293 cells co-transfected with Flag-AT ${ }_{1 \mathrm{~A}} \mathrm{R}$-RlucII and $\beta$-arr2-GFP10 (black circles) or $\beta$-arr2 $\triangle \mathrm{AP} 2-\mathrm{GFP} 10$ (red squares) 
plasmids were stimulated with 100nM AngII and real-time BRET measurements were performed. Graph represents $\triangle$ mBRET values. (a-d) Values are means \pm s.e.m. from three independent experiments (three replicates per condition in each experiment).

Supplementary Figure 8: Barbadin does not prevent basal FAK- $\beta$-arr2 interaction in unstimulated cells. a BRET saturation curves of HEK-293 cells co-transfected with a constant amount of RlucII-FAK plasmid and increasing concentrations of $\beta$-arr2-GFP10 plasmid, incubated for 10 min with DMSO (black circles) or $50 \mu \mathrm{M}$ Barbadin (red squares) before measuring BRET values. b Inverse BRET. HEK-293 cells were co-transfected with a constant amount of $\beta$-arr2-GFP10 plasmid and increasing amounts of RlucII-FAK plasmid as described in the Supplemental Methods. Following treatment with DMSO (black circles) or $50 \mu \mathrm{M}$ Barbadin (red squares) for 10 min, BRET values were obtained and plotted as a function of increasing donor luminescence. (a-b) Values are means \pm s.e.m. from three independent experiments (three replicates per condition in each experiment).

Supplementary Figure 9: Comparison of FAK/ $\beta$-arr2 interaction in response to AT1AR or V2R stimulation. HEK-AT ${ }_{1 \mathrm{~A}} \mathrm{R}$ (a) and HEK-V2R (b) cells were transfected with HA-FAK and GFP or $\beta$-arr-GFP, serum starved and left unstimulated or treated with $1 \mu \mathrm{M}$ AngII or $1 \mu \mathrm{M}$ AVP $(15 \mathrm{~min})$. IPs were performed using anti-GFP antibodies and both IPs and lysates were immunoblotted for HA-FAK and GFP. Data represents mean \pm s.e.m. of the ratio of co-immunoprecipitated HA-FAK to immunoprecipitated $\beta$-arr-GFP normalised to untreated cells and set to one from four independent experiments. (***P value $<0.001, t$-test).

Supplementary Figure 10: $\beta$-arr2C1 (317-410) downregulates FAK activation in response to AngII stimulation. HEK-AT ${ }_{1 \mathrm{~A}} \mathrm{R}$ cells were transfected with GFP, GFP- $\beta$-arr2C1(317-410) or GFP- $\beta$-arr2C1mut (mutated AP-2 and clathrin binding sites), serum starved and stimulated with 100nM AngII for 5 min. Lysates were immunoblotted for pY397-FAK, FAK and GFP. Data show mean \pm s.e.m. of pY397-FAK/FAK values normalized to untreated cells transfected with GFP and set to one, from three independent experiments. (** $P$ value $<0.01$; one-way Anova, Bonferroni). 
a
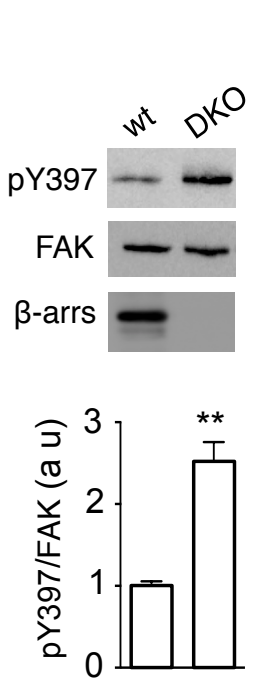

C
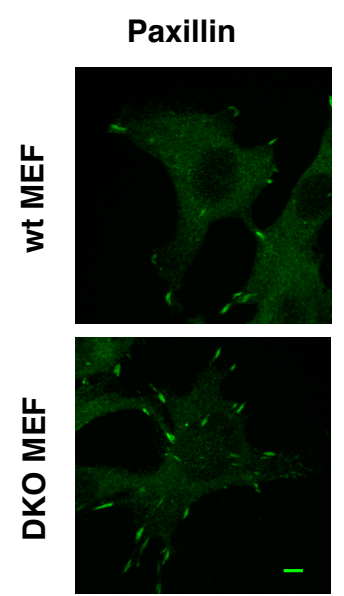

b
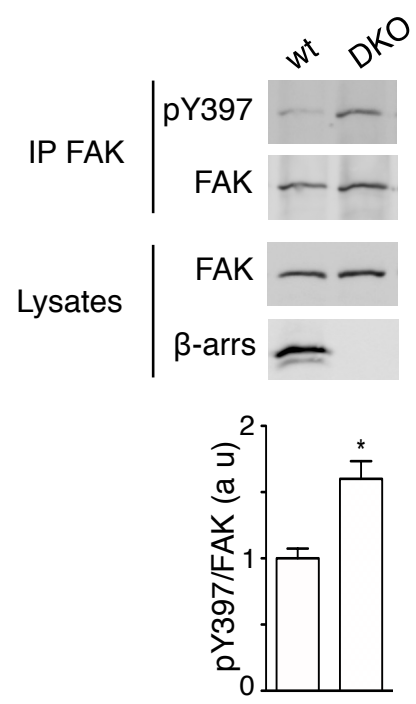

\section{pY397}
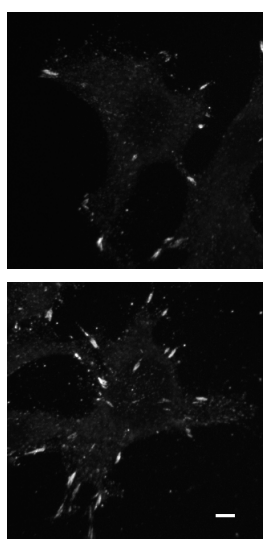

Merge
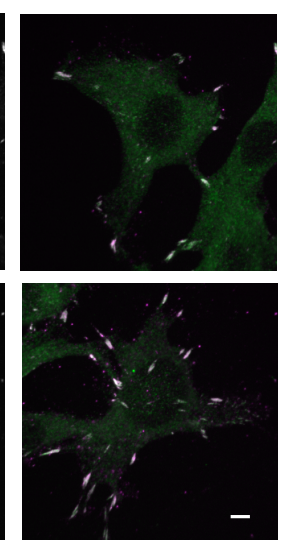

d

wt MEF

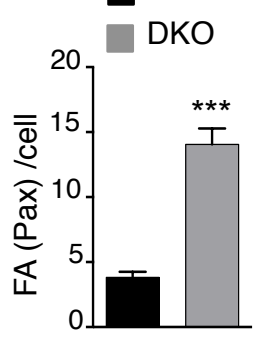

e

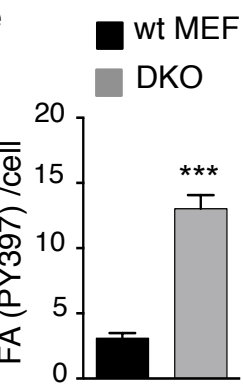

f

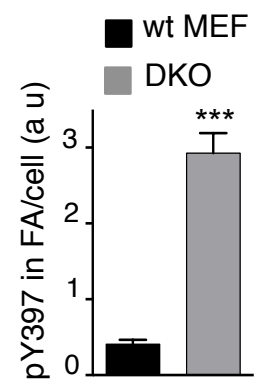

Figure 1. $\beta$-arrs regulate FAK autophosphorylation and focal adhesion number. 
a

HA-FAK: $\quad+\quad+\quad+$

ßarr1-GFP: $\quad+\quad+$

ßarr2-GFP: - - +

GFP:

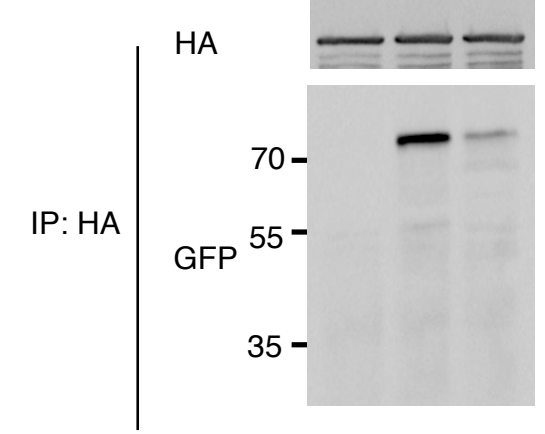

d

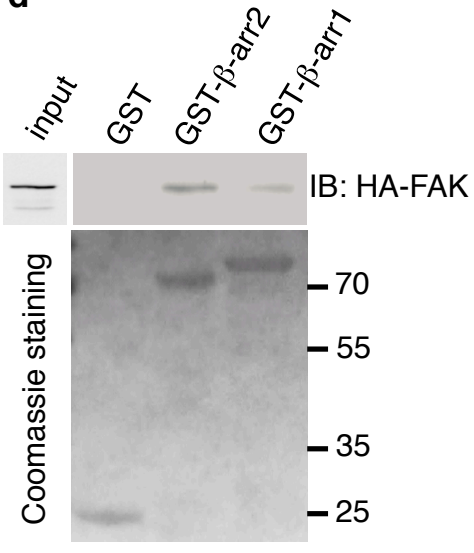

C

$\begin{array}{cc}\text { Gal4 BD } & \text { Gal4AD }-\mathrm{His}+\mathrm{His} \\ \text { Gal4 BD } & \text { Gal4 AD } \\ \text { Gal4 BD } & \text { FAK } \\ \beta \text {-arr2 } & \text { FAK } \\ \beta \text {-arr2 } & \text { Gal4 AD }\end{array}$

e

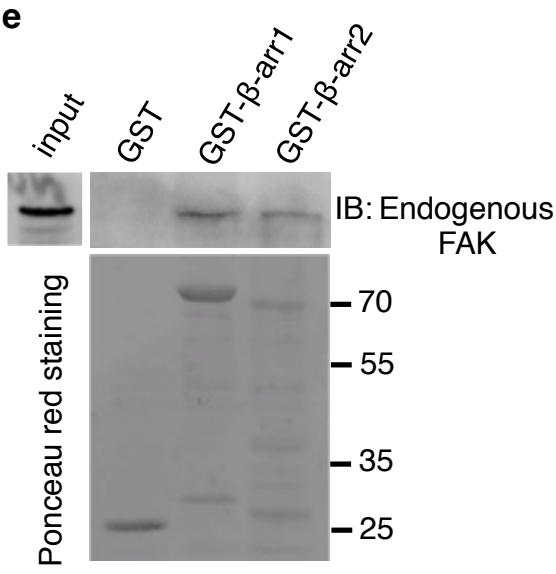

b HA-FAK: $\quad-\quad-+++$

Myc- $\beta$-arr $1: \quad-+-\quad+-$

Мyс- $\beta$-arr 2: $\quad-\quad+\quad-\quad+$

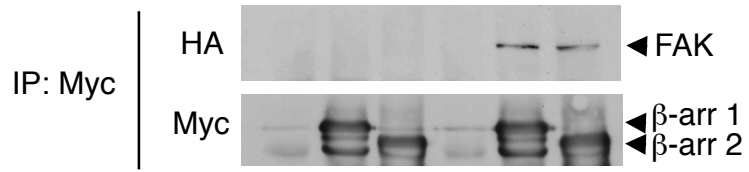

f
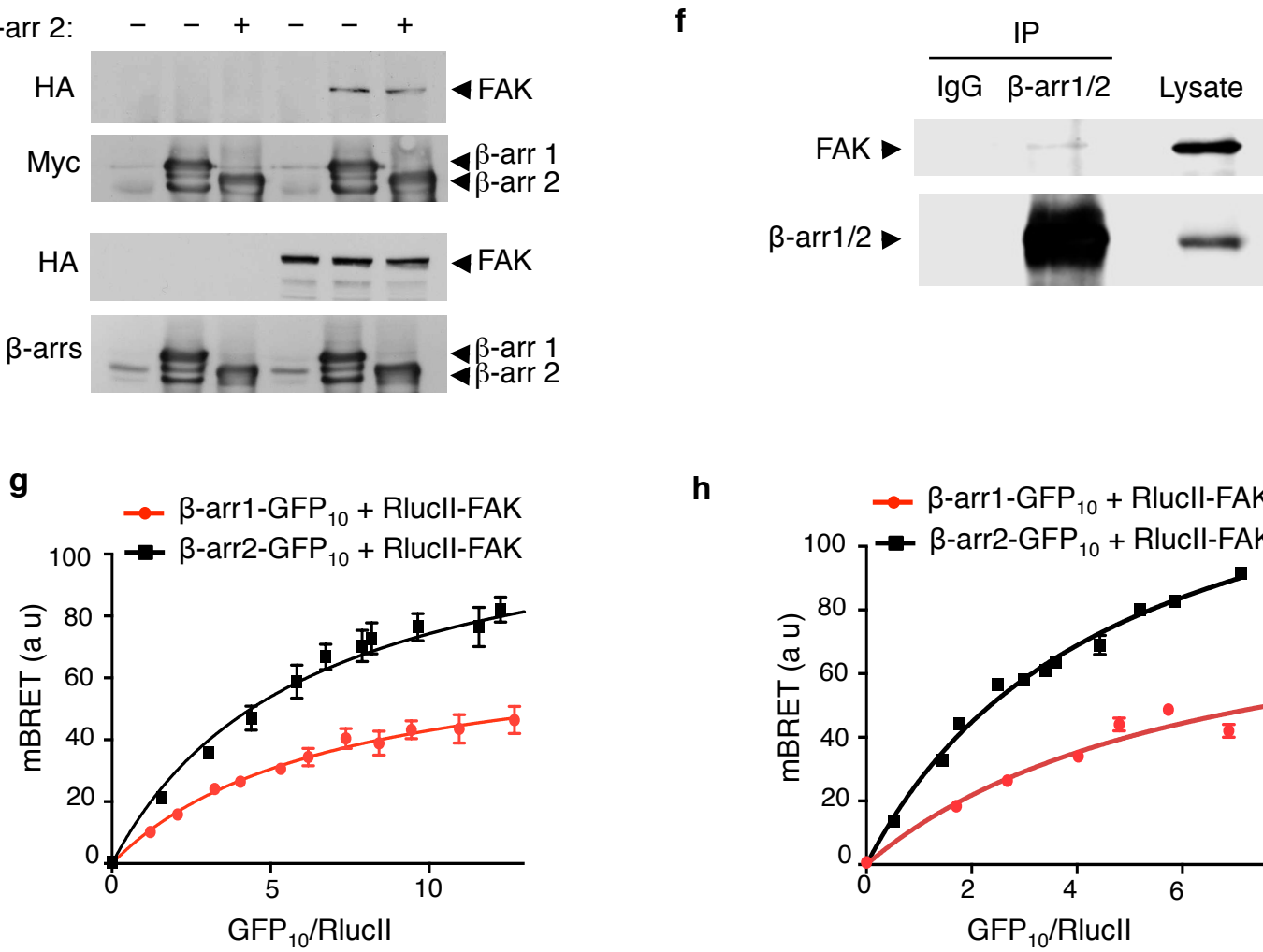

h

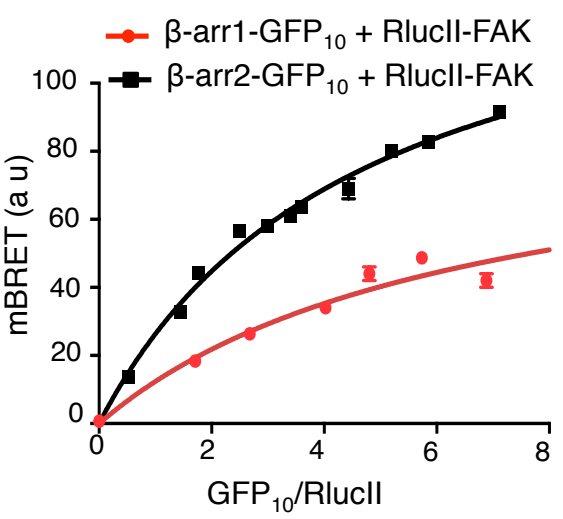

Figure 2. FAK interacts with $\beta$-arrs. 
a
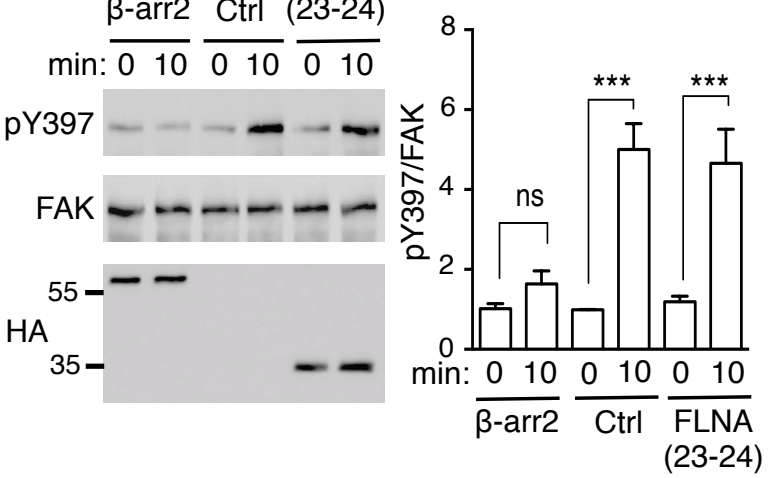

b

siRNA: $\operatorname{ctrl} \beta$-arr2 $\beta$-arr1 $\beta$-arr1/2
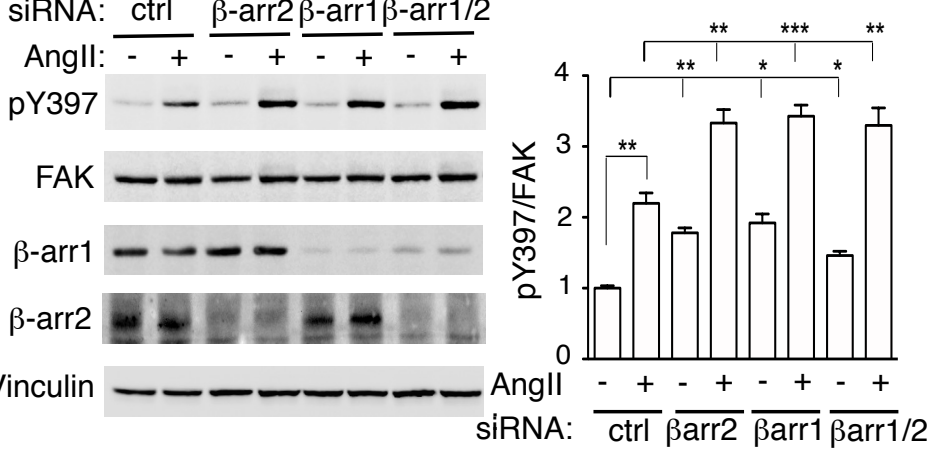

C

Control
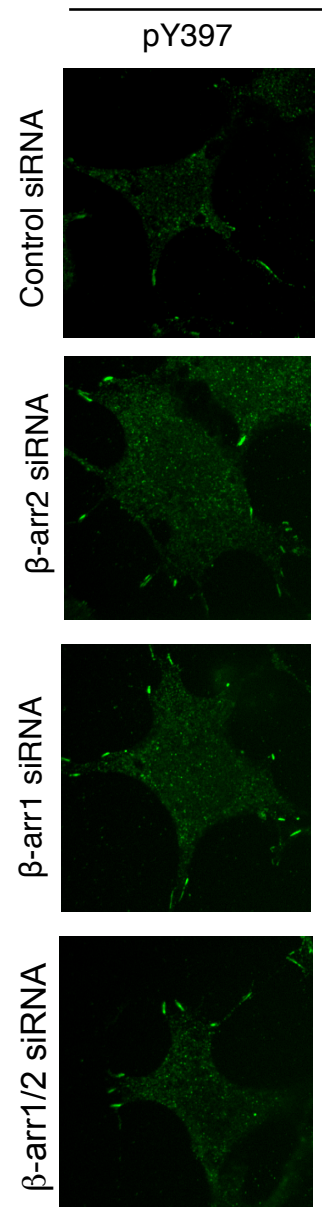

d

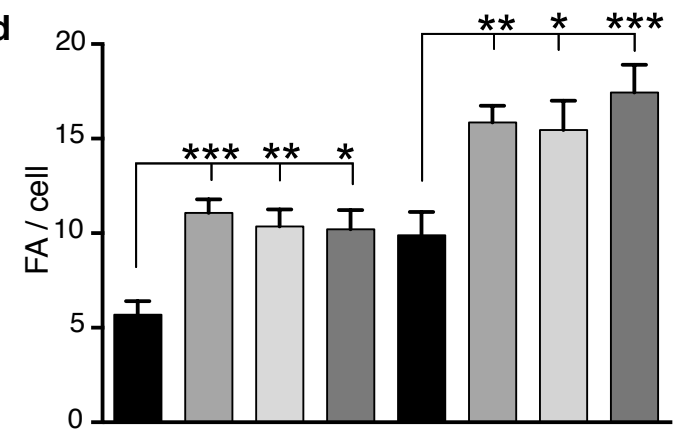

siRNA:
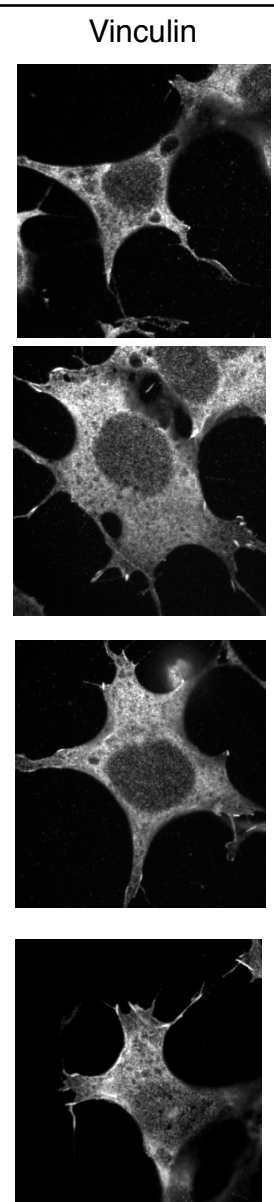
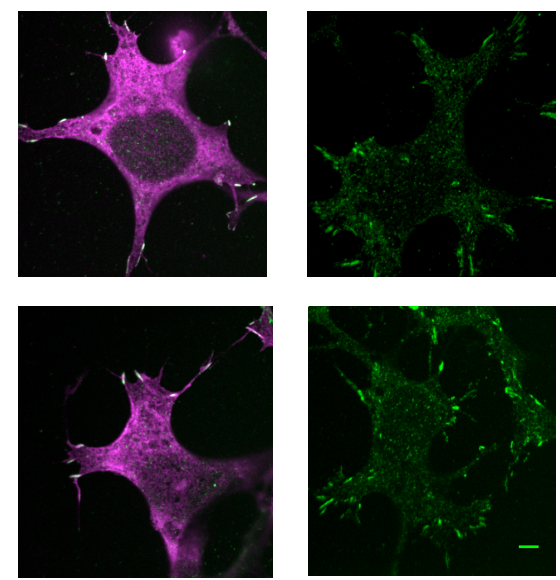

e

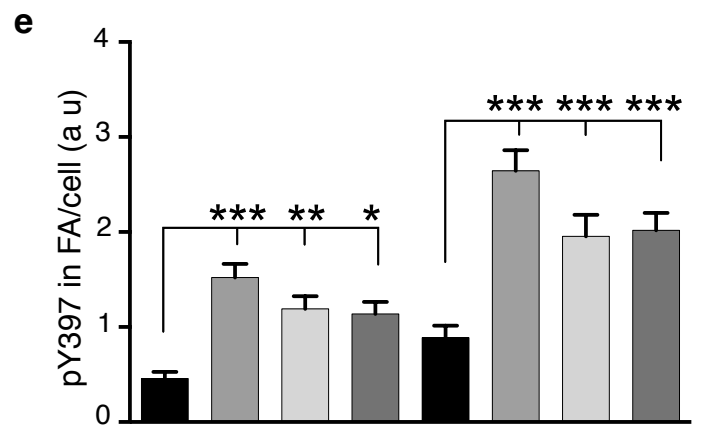

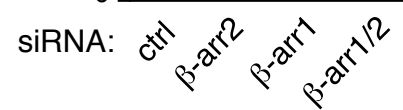

Control

ANG II
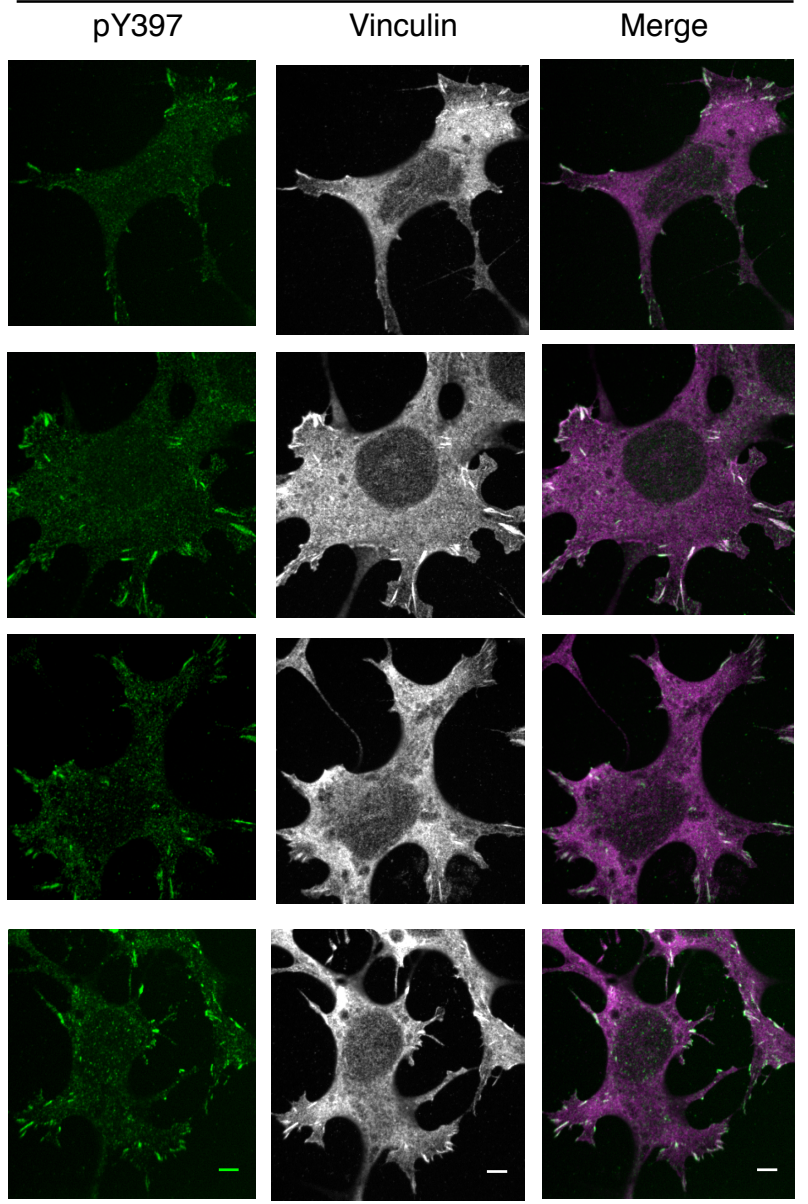

$* * * * * * * * *$

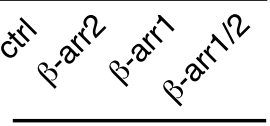

Ang II

Figure 3. $\beta$-arrs regulate FAK catalytic activity and focal adhesion number. 
Alexander et al-Enslen, Fig. 4

a

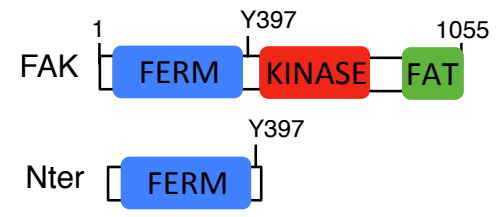

$\Delta \mathrm{Nter}$

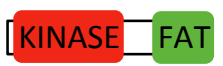

376-1055

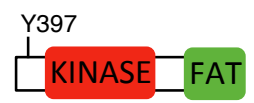

b

Gal4 BD Gal4AD - His + His

$\beta$-arr2 Nter

Gal4 BD Nter

$\beta$-arr2 $\quad \Delta$ Nter

Gal4 BD $\Delta$ Nter

c

HA-FAK: $-+-\quad+\quad+-+$

HA-FAK-Nter: $-\quad+\quad+\quad+\quad+-+$

myc- $\beta$-arr1: $-\quad-+++--$

myс- $\beta$-arr2: $\quad-\quad-\quad-\quad-\quad+++$

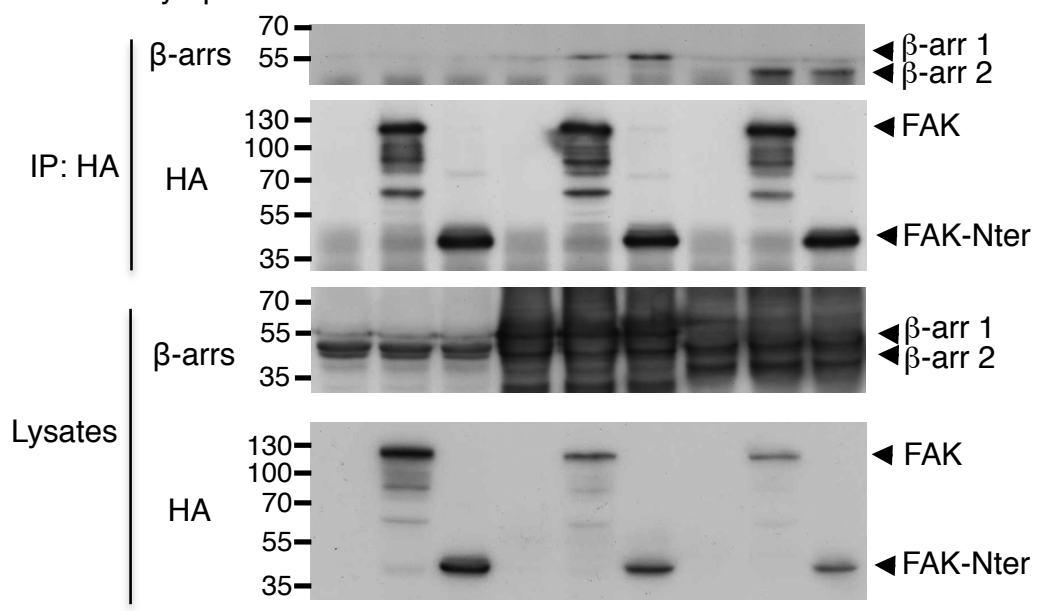

e d

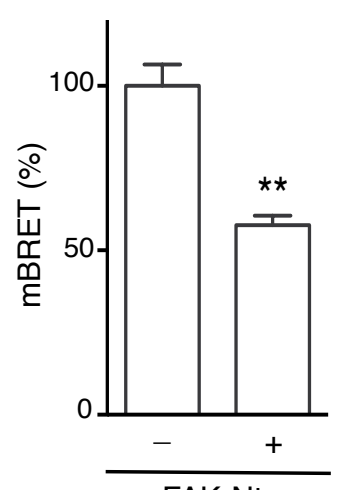

FAK-Nter
FAK-Nter

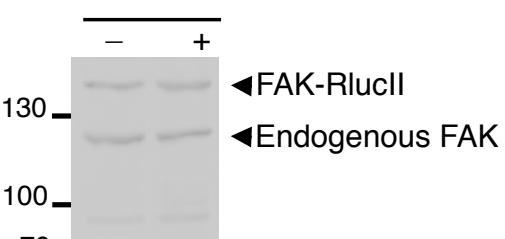

FAK 70_

HA-FAK: $+\quad++$

HA-FAK (376-1055): $-\quad+\quad+$

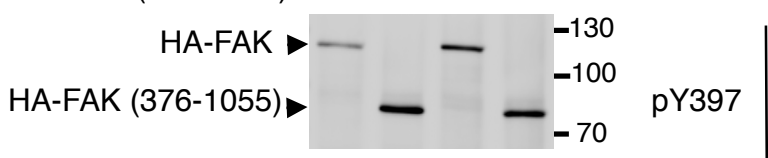

HA-FAK
HA-FAK (376-1055)
$-\quad-\quad \begin{aligned}-130 \\ -100\end{aligned}$ FAK

$=--\frac{-a r r s}{-}($ lysates)

siRNA: $\overline{\text { control }} \overline{\beta \text {-arrs }}$

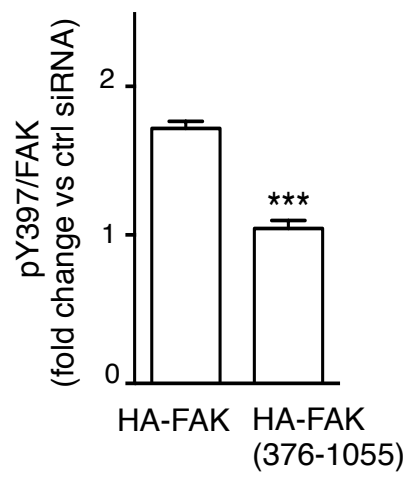

Figure 4. FAK $\mathrm{N}$-terminal domain is necessary for $\beta$-arr interaction. 
Alexander et al-Enslen, Fig. 5

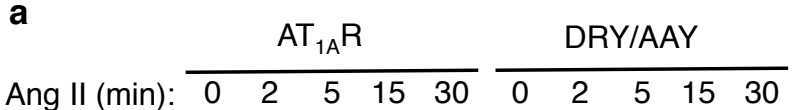

pY397

FAK - - - - - - - -

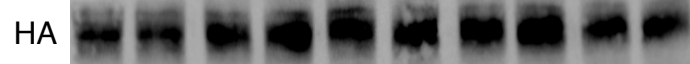
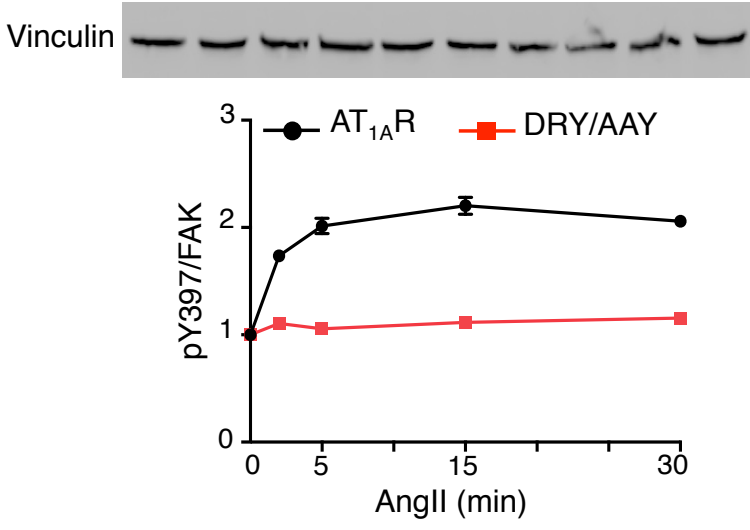

c
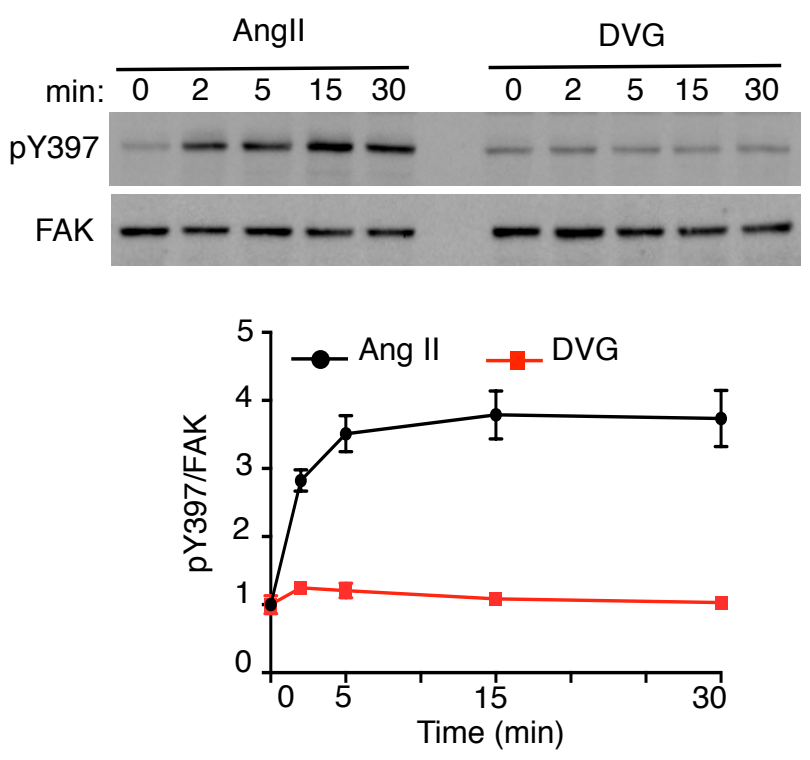

b

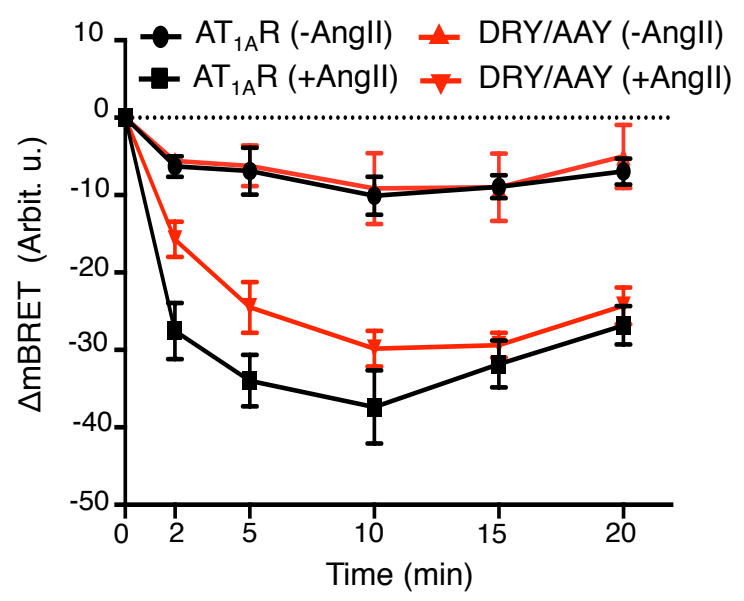

d

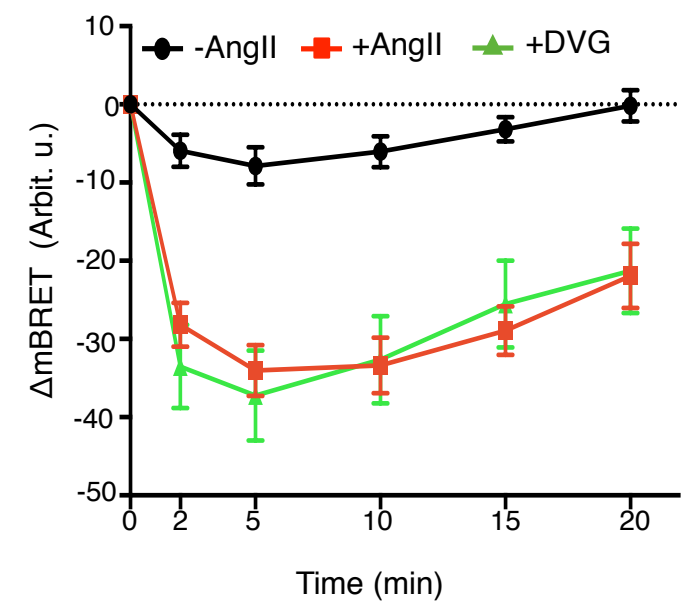

Figure 5. FAK autophosphorylation in response to Angll stimulation is mediated by a G protein-dependent pathway. 
Alexander et al-Enslen, Fig. 6

a HA-FAK: $\frac{\text { IP: GFP }}{+++}$

Barr2-GFP: -++

GFP: + - -

Angll:
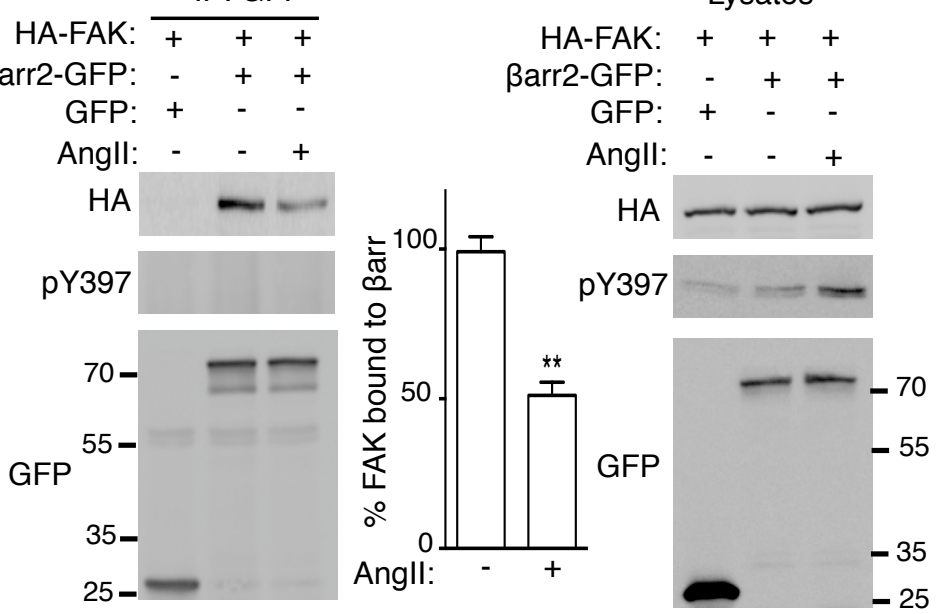

C

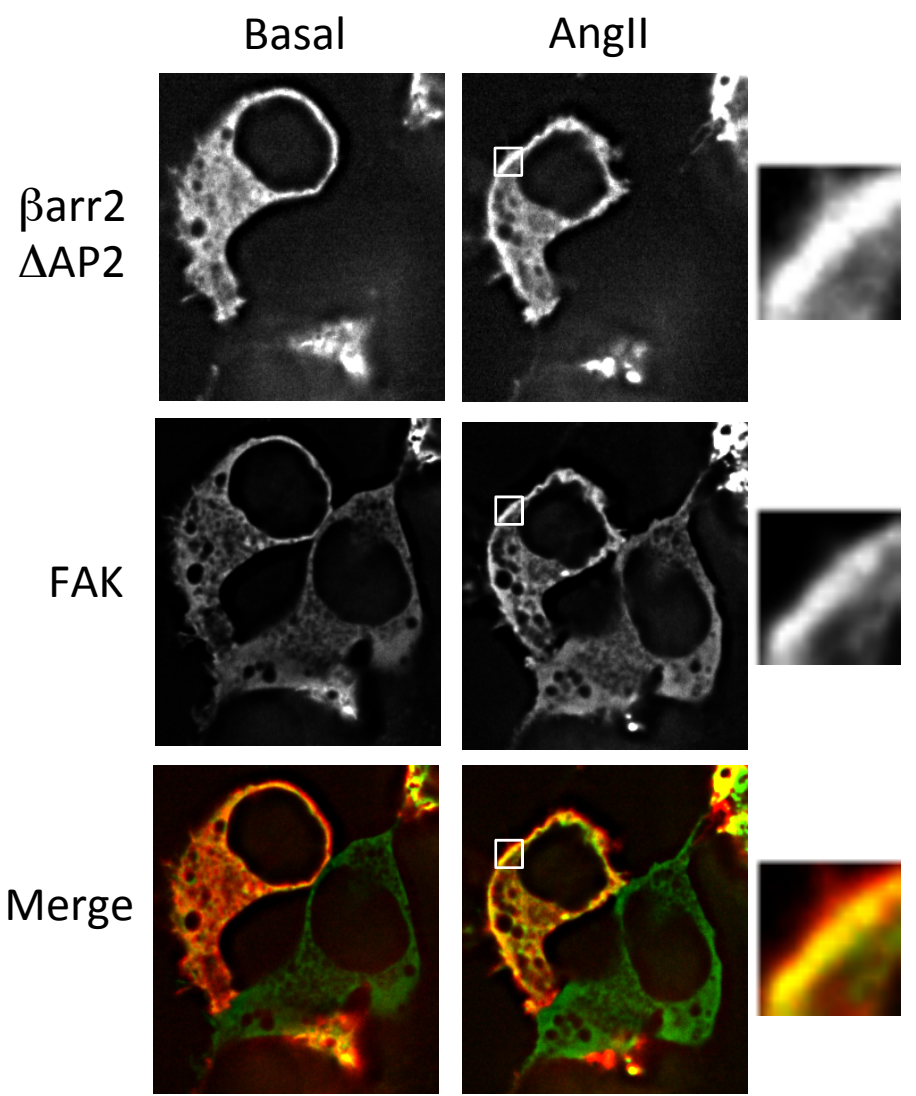

e

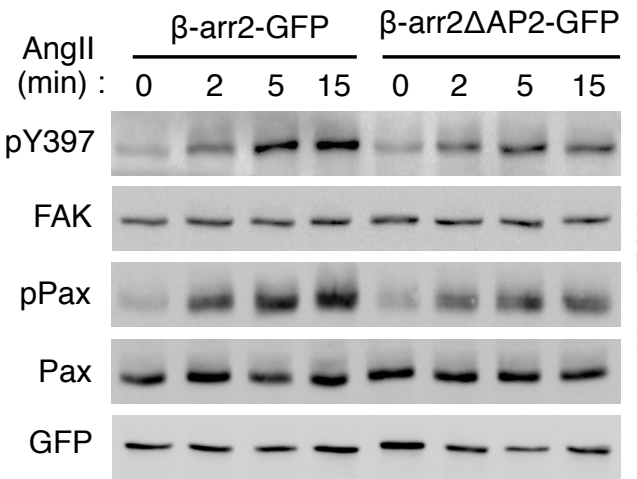

Figure 6. Interaction of $\beta$-arr2 with AP-2 upon Angll stimulation releases FAK from $\beta$-arr2 and its constitutive inhibition over FAK. b

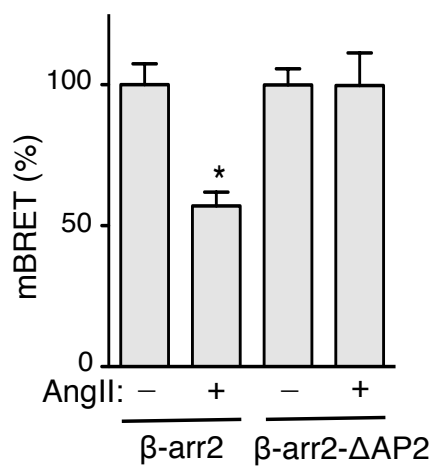

d

HA-FAK: +++++

GFP: + - - - -

ßarr2-GFP: $\quad-\quad+\quad+\quad-$

ßarr2 $\triangle$ AP2-GFP: - $\quad-\quad-\quad+\quad+$

IP: GFP

Angll: - -+-+

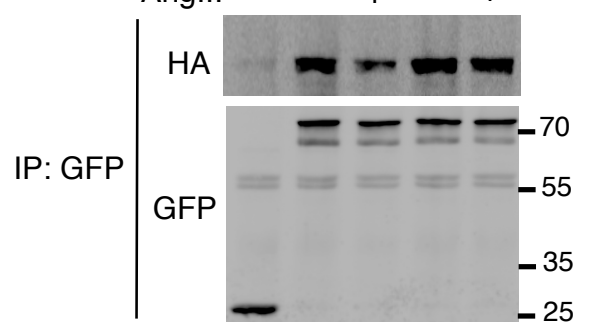

Lysates
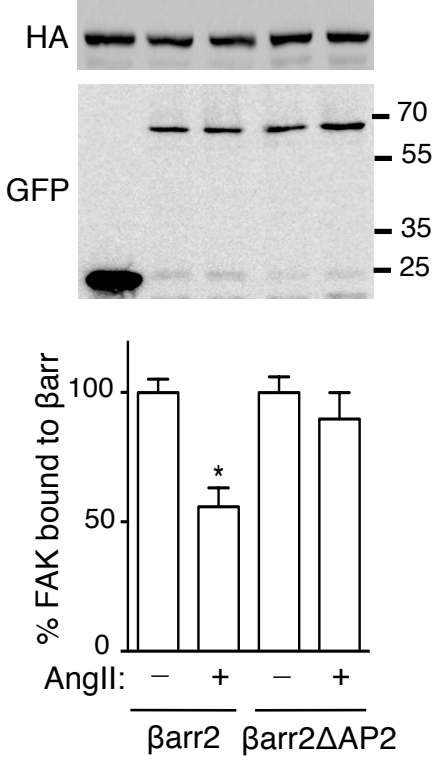

$\longrightarrow \beta$-arr2-GFP

$-\beta$-arr2 $\triangle$ AP2-GFP
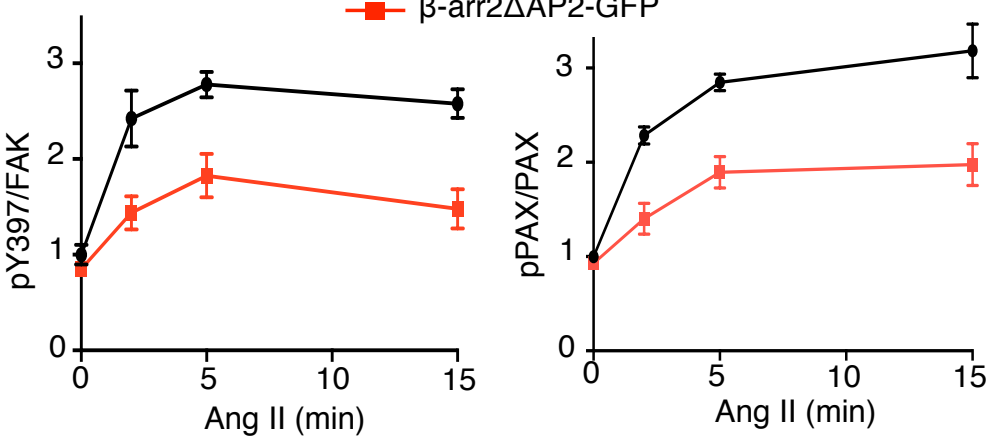
Alexander et al-Enslen, Fig. 7

a

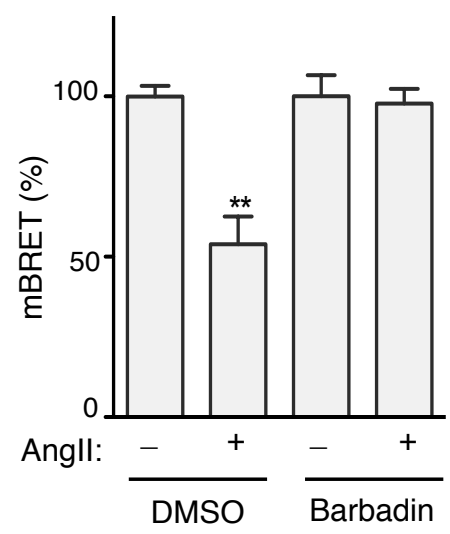

b

Ang II (min): $\begin{array}{lllllllllll}0 & 2 & 5 & 15 & 30 & & 0 & 2 & 5 & 15 & 30\end{array}$
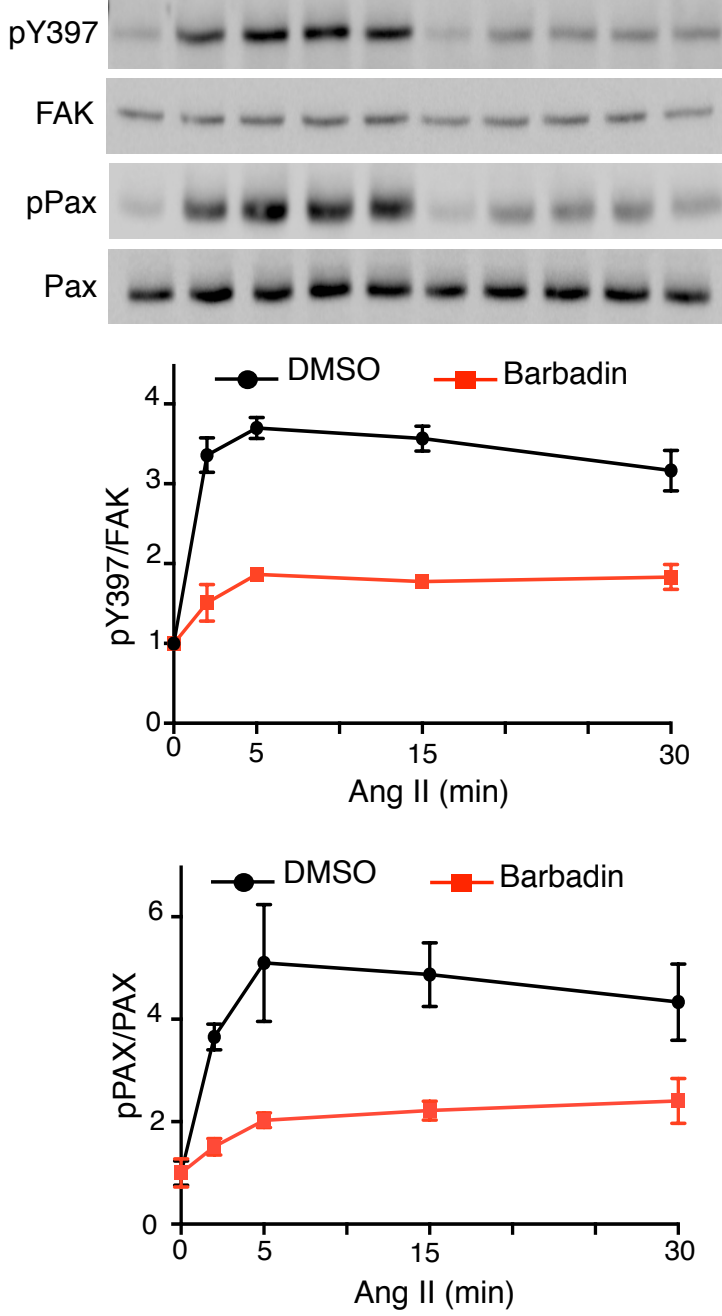

C
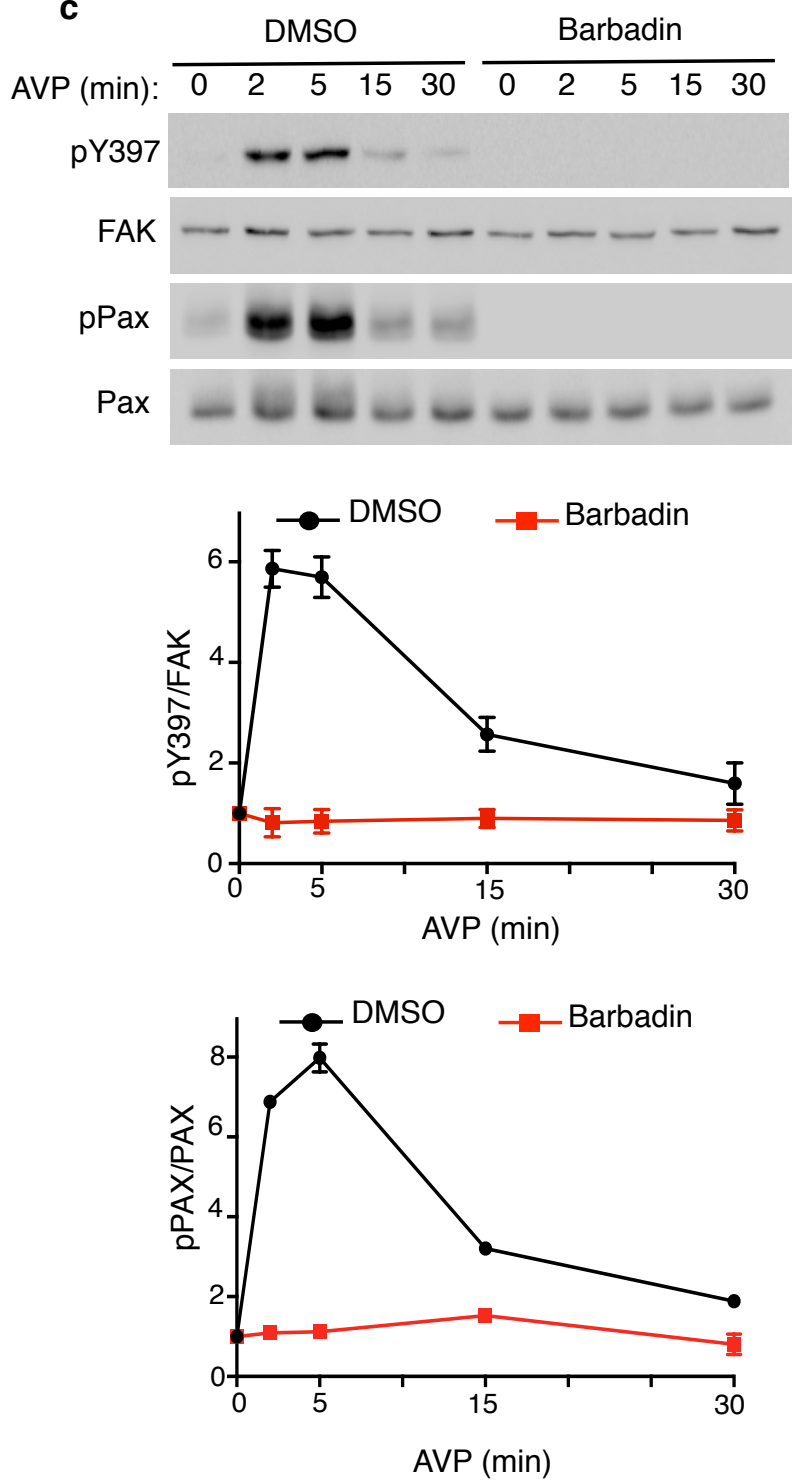

Figure 7. Inhibition of $\beta$-arr2-AP2 interaction downregulates FAK activation in response to Angll and AVP stimulation. 


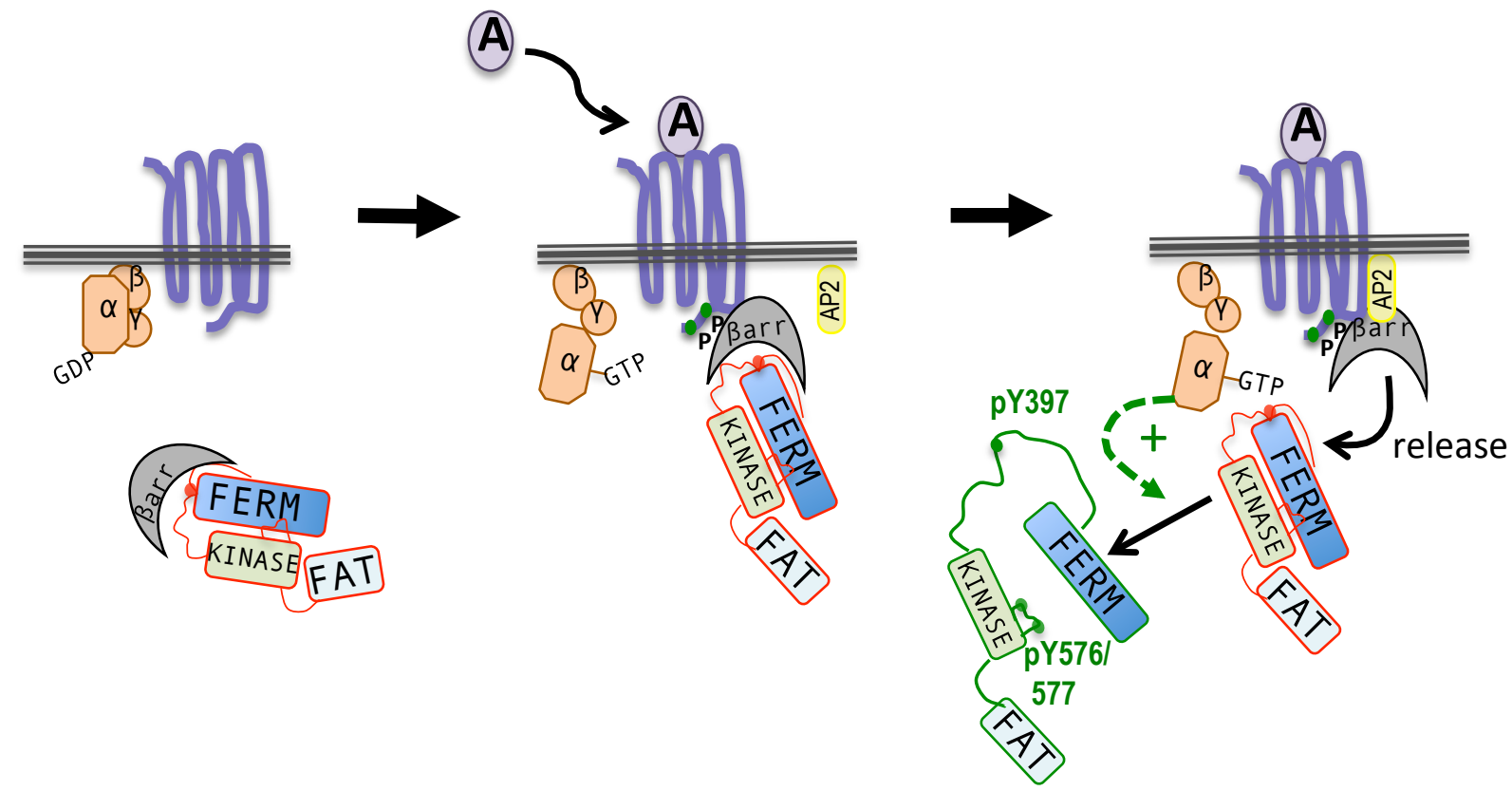

Figure 8. Schematic model for the regulation of FAK activity by $\beta$-arrs under basal and GPCR-stimulated conditions. 

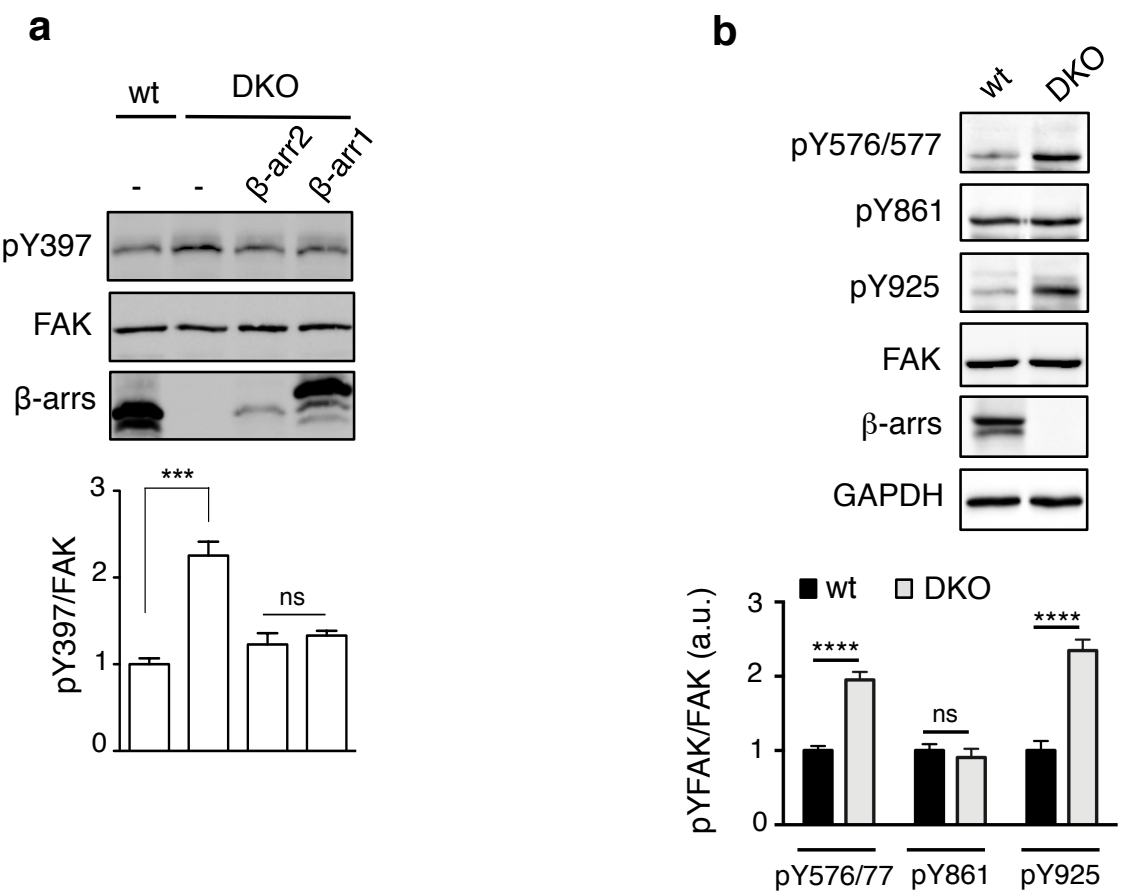

Supplementary Figure 1

Alexander et al- Enslen 
Alexander et al- Enslen Supplementary Fig. 2

a

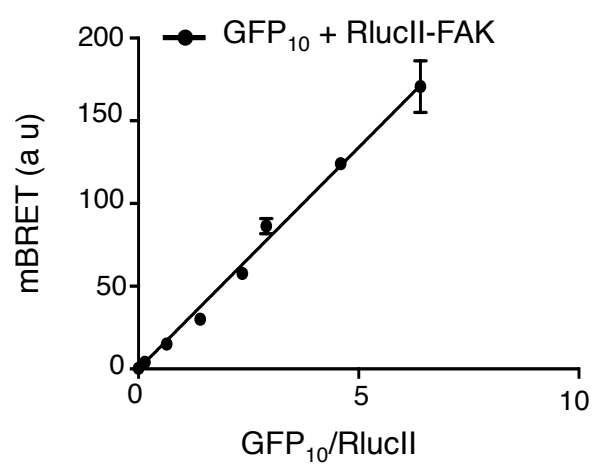

b

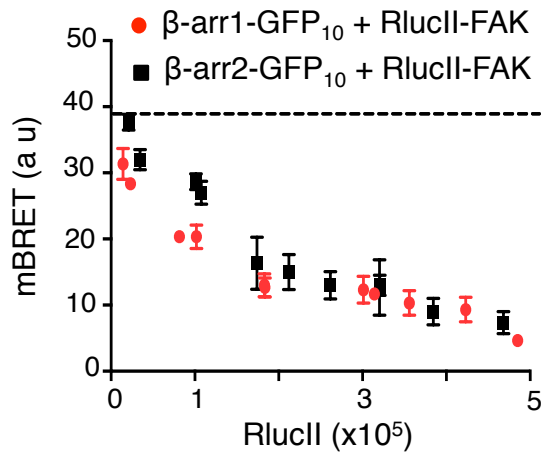

Supplementary Figure 2

Alexander et al- Enslen 

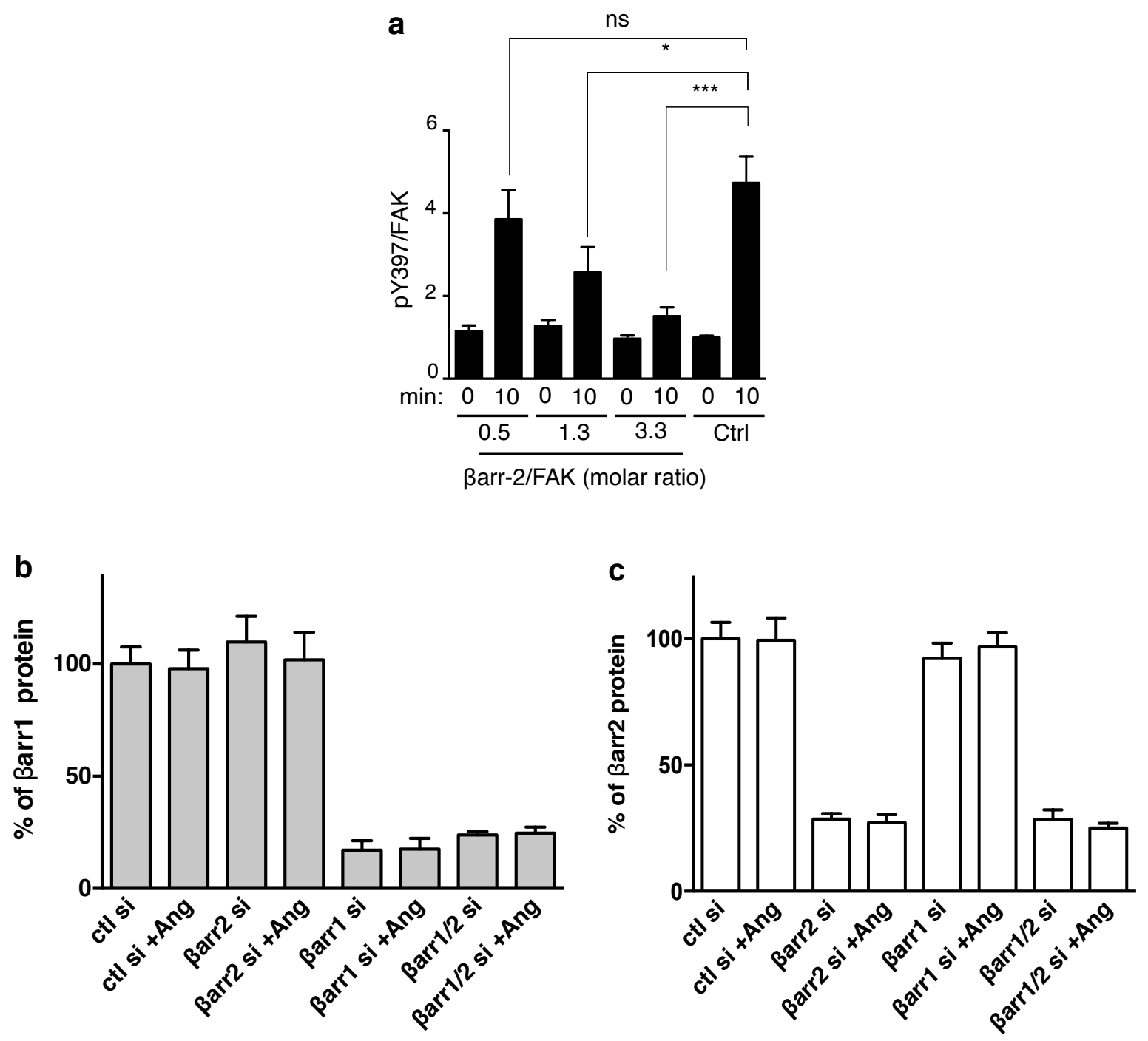

Supplementary Figure 3

Alexander et al- Enslen 
a Angll (min) :

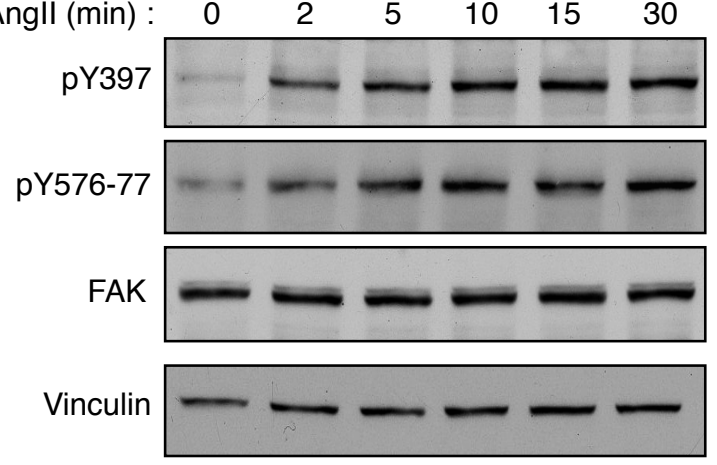

b

FAK
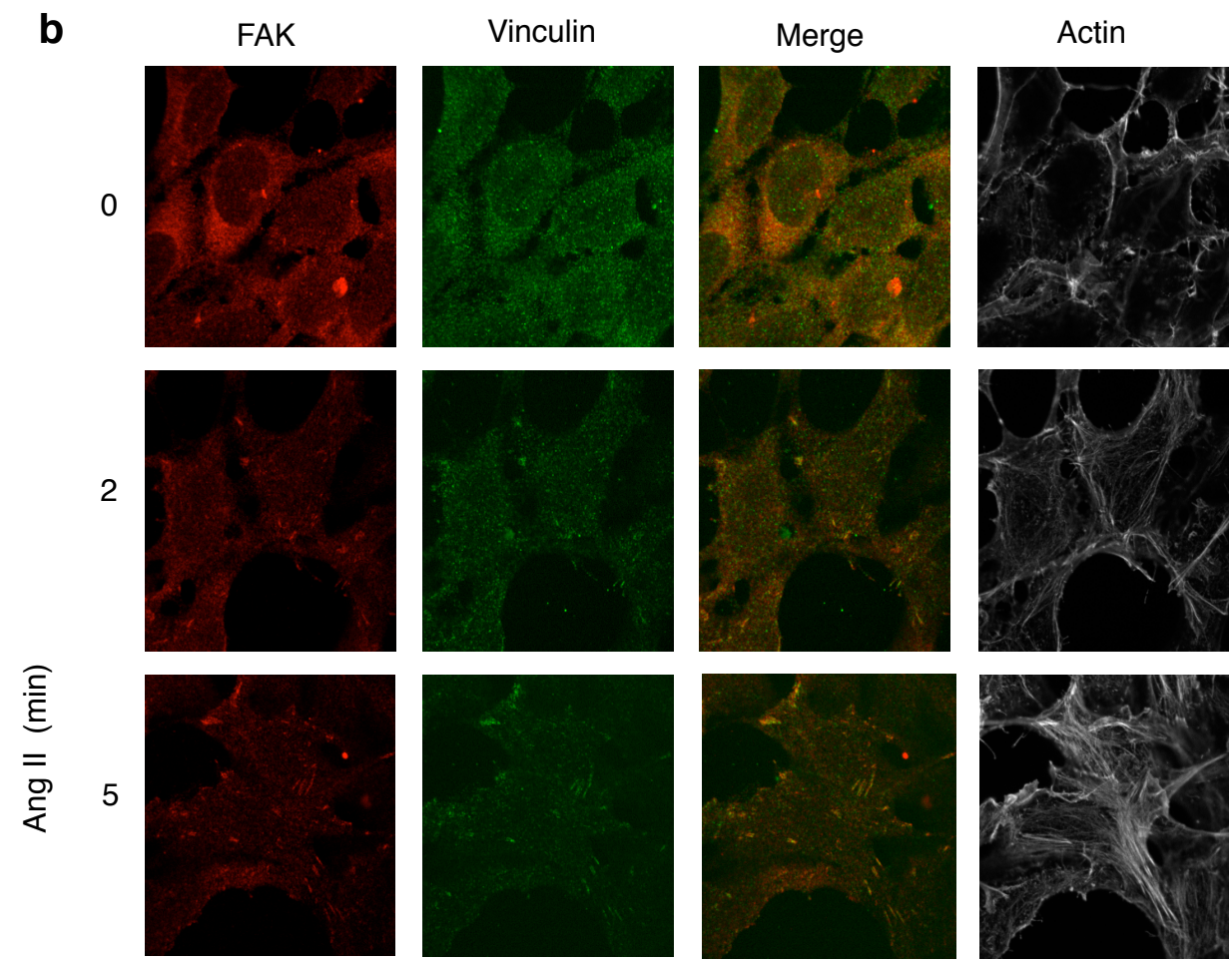

15
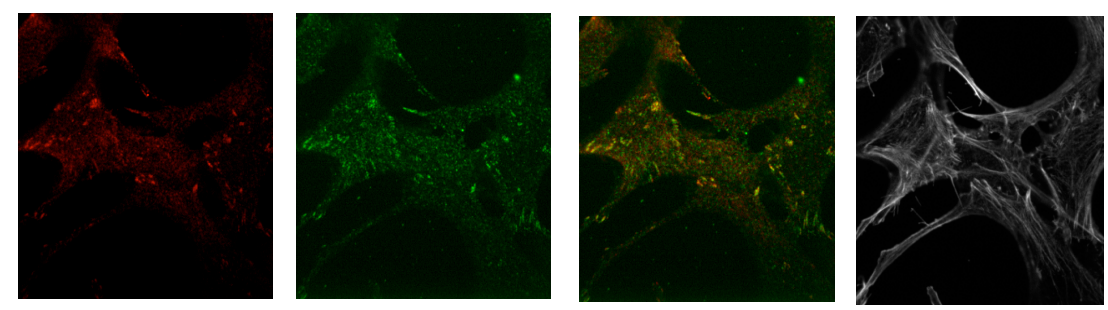

30
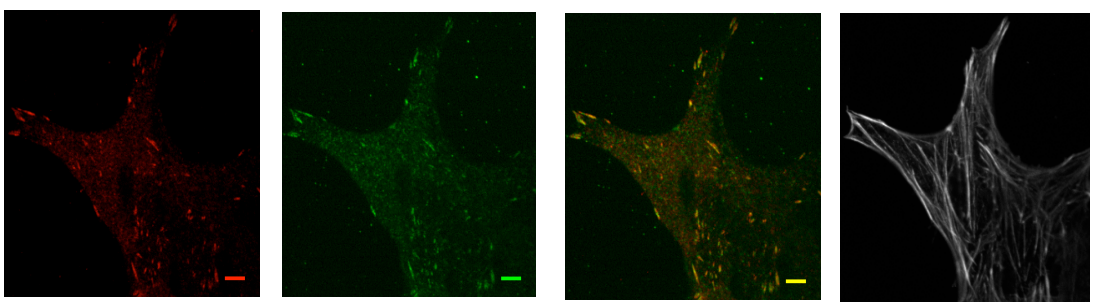

Supplementary Figure 4 Alexander et al- Enslen 
a

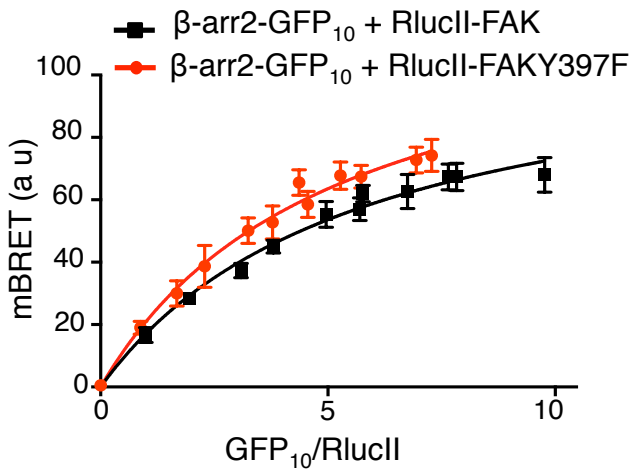

b

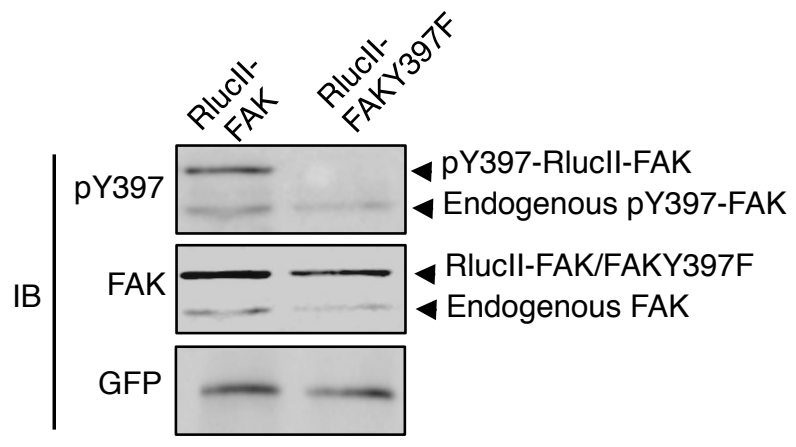

Supplementary Figure 5

Alexander et al- Enslen 


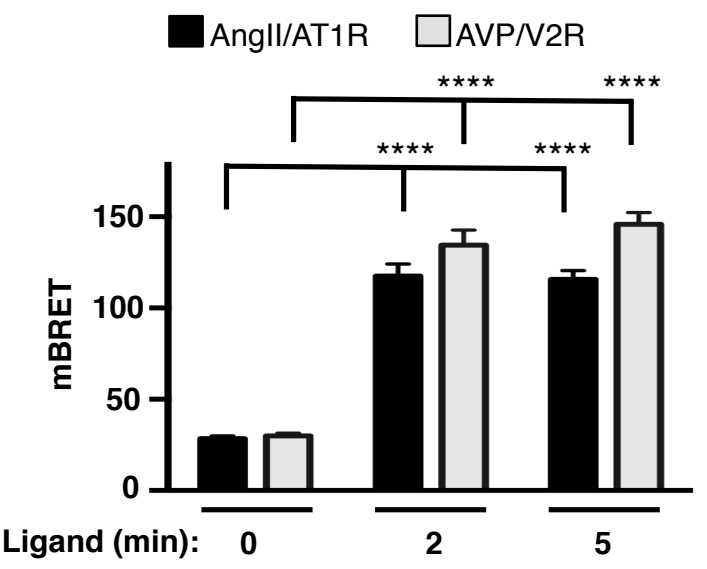

Supplementary Figure 6

Alexander et al- Enslen 

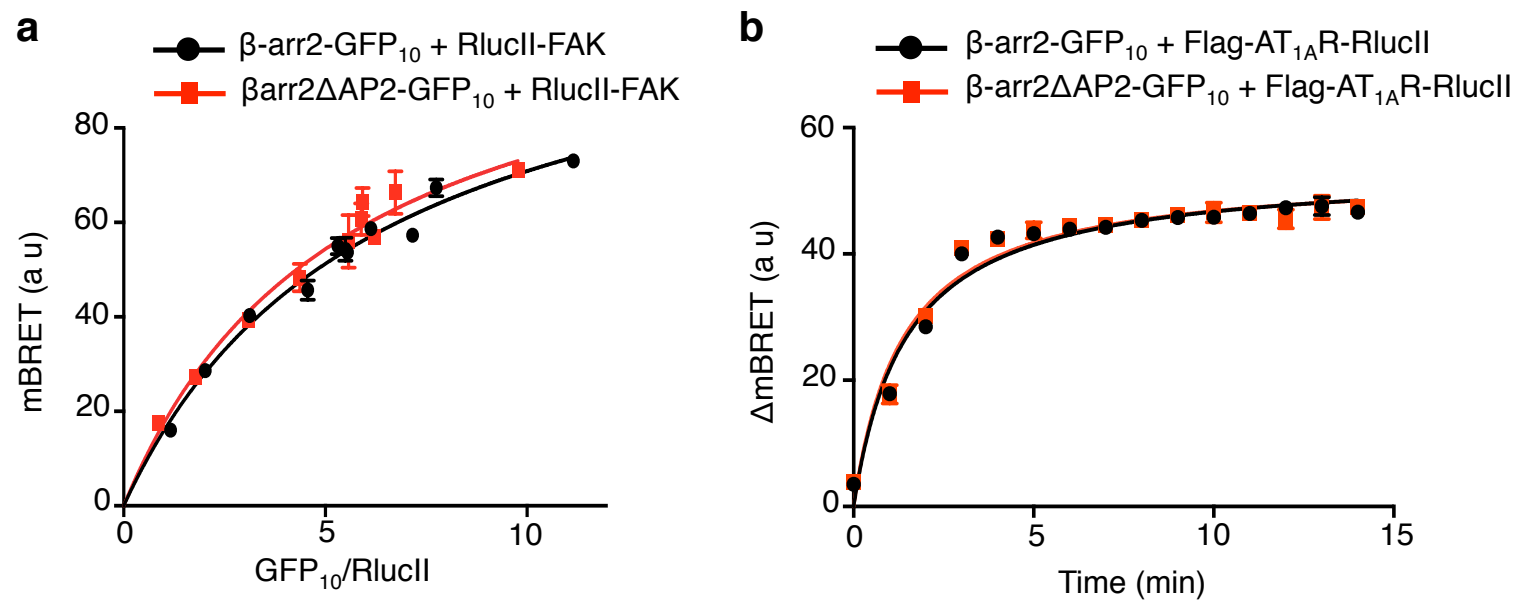

Supplementary Figure 7

Alexander et al- Enslen 
a

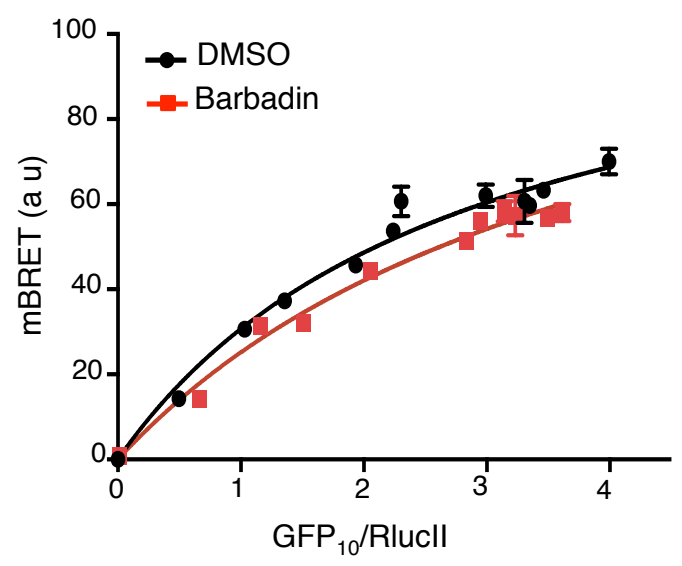

b

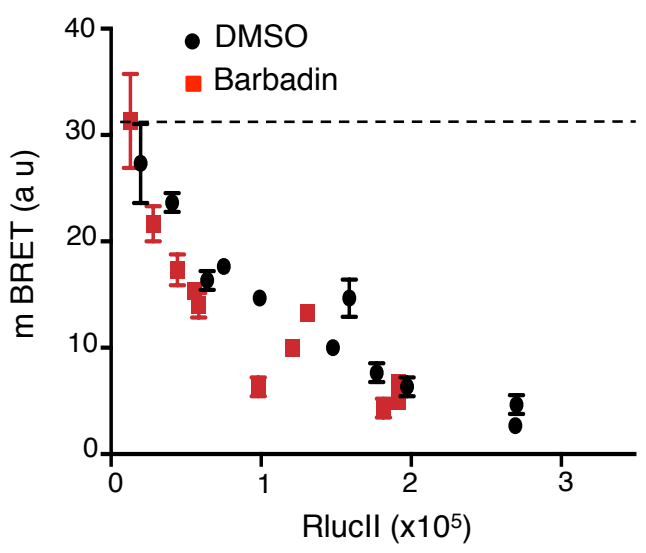

Supplementary Figure 8

Alexander et al- Enslen 
a
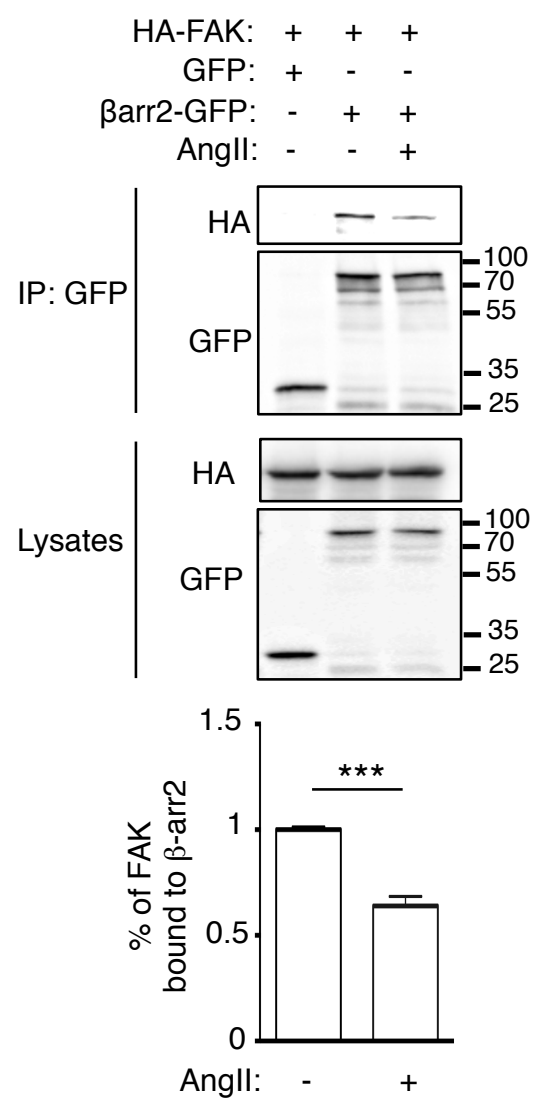

b
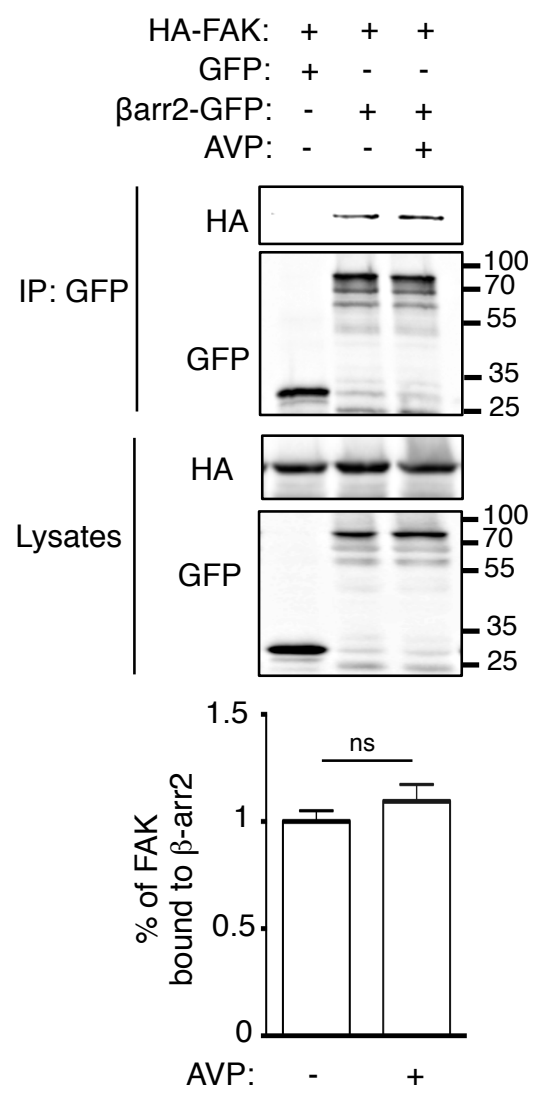

Supplementary Figure 9

Alexander et al- Enslen 

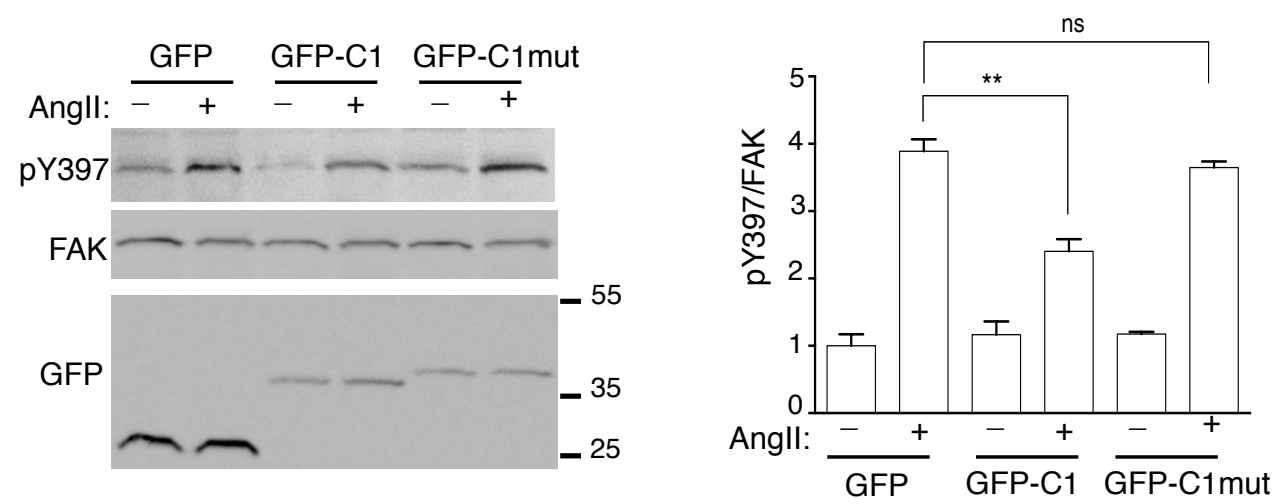

Supplementary Figure 10

Alexander et al- Enslen 


\begin{tabular}{|c|c|}
\hline Plasmid & Primers \\
\hline HA-FAK-Nter (1-402) & $\begin{array}{l}\text { Forward primer: } \\
\text { 5'CATCTAGCAAAAGAATGGCTGCAGCATATCCATACGACGTCCCGGACT } \\
\text { ACGCAGCTGCTTATCTTGA-3' } \\
\text { Reverse primer: } \\
\text { 5'-TCAAGATAAGCAGCTGCGTAGTCCGGGACGTCGTATGGATATGCTGC } \\
\text { AGCCATTCTTTTGCTAGATG-3' }\end{array}$ \\
\hline HA-FAK- $\Delta$ Nter & $\begin{array}{l}\text { Forward primer: } \\
\text { 5'CACAGAATTCATGTATCCATACGACGTCCCGGACTACGCCGAGGAAGACACAA } \\
\text { C-3' } \\
\text { Reverse primer: 5'-ACCTGGTACCCCACCCGATCCAGAG-3' }\end{array}$ \\
\hline HA-FAK(376-1055) & $\begin{array}{l}\text { Forward primer: 5'-GCACGGAATTCCTTTGGCCAACAATGAAAAGC-3' } \\
\text { Reverse primer: 5'-CGGCGGTACCAGAGTTTTCTGAACAC-3' }\end{array}$ \\
\hline Rlucll-FAK & $\begin{array}{l}\text { Forward primer: 5'-GAACCGGTCGCCACCATGAC-3' } \\
\text { Reverse primer: 5'-GAGATCCGGACTGCTCGTTCTT-3' }\end{array}$ \\
\hline Rlucll-FAKY397F & $\begin{array}{l}\text { Forward primer: 5'- GAGACAGATGACTTTGCCGAGATCG -3' } \\
\text { Reverse primer: 5'- CGATCTCGGCAAAGTCATCTGTCTC-3' }\end{array}$ \\
\hline FAK-RLucll & $\begin{array}{l}\text { Forward primer : 5'-GATCCGCTAGCATGGCAGCTGCTTATC-3' } \\
\text { Reverse primer : 5'-ATATGGTACCGTGTGGCCGTGTCTG-3' }\end{array}$ \\
\hline Gal4 AD FAK & $\begin{array}{l}\text { Forward primer: 5'-TCGGGATCCTTGCTGCTTATCTT-3' } \\
\text { Reverse primer: 5'-GGTGGATCCAGAGTTTTCTGAA-3' }\end{array}$ \\
\hline Gal4 AD FAK-Nter & $\begin{array}{l}\text { Forward primer: 5'-TCGGGATCCTTGCTGCTTATCTT 3' } \\
\text { Reverse primer: 5'-GAAGGATCCTTAATCGATGATCTCGGCA-3' }\end{array}$ \\
\hline Gal4 AD FAK- $\Delta$ Nter & $\begin{array}{l}\text { Forward primer: 5'-GGAGAATTCGAGGAAGACACATA-3' } \\
\text { Reverse primer: 5'-GGTGGATCCAGAGTTTTCTGAA-3' }\end{array}$ \\
\hline$\beta$-arr $\triangle A P-2-G F P 10$ & $\begin{array}{l}\text { Forward primer: 5'-ACTTTGCCCGGCTTGCGCTGAAGGGGATG-3' } \\
\text { Reverse primer: 5'-CATCCCCTTCAGCGCAAGCCGGGCAAAGT-3' }\end{array}$ \\
\hline mCherry- $\beta$-arr $\triangle \mathrm{AP}-2$ & $\begin{array}{l}\text { Forward primer: 5'-GAGGACTTTGCCCGGCTTGCGCTTAAGGGGATGAAGGATG-3' } \\
\text { Reverse primer: 5'-CATCCTTCATCCCCTTAAGCGCAAGCCGGGCAAAGTCCTC-3' }\end{array}$ \\
\hline 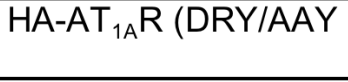 & $\begin{array}{l}\text { Forward primer: 5'-TGTCTCAGCATCGCCGCCTACCTGGCCATC-3' } \\
\text { Reverse primer: 5'-GATGGCCAGGTAGGCGGCGATGCTGAGACA-3' }\end{array}$ \\
\hline
\end{tabular}

Supplementary Table 1. PCR Primers used to construct the different plasmids mentioned in the Methods section 